A combined ultrasonic flow meter and binary vapour mixture analyzer for the ATLAS silicon tracker

This content has been downloaded from IOPscience. Please scroll down to see the full text. 2013 JINST 8 P02006

(http://iopscience.iop.org/1748-0221/8/02/P02006)

View the table of contents for this issue, or go to the journal homepage for more

Download details:

IP Address: 131.169.3.59

This content was downloaded on 19/02/2014 at 12:57

Please note that terms and conditions apply. 


\title{
A combined ultrasonic flow meter and binary vapour mixture analyzer for the ATLAS silicon tracker
}

\author{
R. Bates, ${ }^{a}$ M. Battistin, ${ }^{b}$ S. Berry, ${ }^{b}$ J. Berthoud, ${ }^{b}$ A. Bitadze, ${ }^{a}$ P. Bonneau, ${ }^{b}$ \\ J. Botelho-Direito ${ }^{b}$ N. Bousson, ${ }^{c}$ G. Boyd,${ }^{d}$ G. Bozza, ${ }^{b}$ E. Da Riva, ${ }^{b}$ C. Degeorge ${ }^{e}$ \\ C. Deterre, ${ }^{f}$ B. DiGirolamo, ${ }^{b}$ M. Doubek, ${ }^{g}$ D. Giugni, ${ }^{h}$ J. Godlewski, ${ }^{b}$ G. Hallewell, ${ }^{c}, 1$ \\ S. Katunin, ${ }^{i}$ D. Lombard, ${ }^{b}$ M. Mathieu, ${ }^{c}$ S. McMahon, ${ }^{j}$ K. Nagai, ${ }^{k}$ \\ E. Perez-Rodriguez, ${ }^{b}$ C. Rossi, ${ }^{l}$ A. Rozanov, ${ }^{c}$ V. Vacek, ${ }^{f}$ M. Vitek ${ }^{f}$ and L. Zwalinski ${ }^{b}$
}

${ }^{a}$ SUPA School of Physics and Astronomy, University of Glasgow,

Glasgow, G62 7QB, United Kingdom

${ }^{b}$ CERN,

1211 Geneva 23, Switzerland

${ }^{c}$ Centre de Physique des Particules de Marseille, Aix-Marseille Université, CNRS/IN2P3,

163 Avenue de Luminy, 13288 Marseille Cedex 09, France

${ }^{d}$ The Homer L. Dodge Department of Physics and Astronomy, University of Oklahoma, 440 West Brooks Street, Norman, OK 73019, United States of America

' Indiana University, Department of Physics, 727 East Third St., Bloomington, IN 47405-7105, United States of America

${ }^{f}$ Deutsches Elektronen-Synchrotron , Notkestraße 85, D-22607

Hamburg, Germany

${ }^{g}$ Czech Technical University in Prague, Department of Applied Physics,

Technická 4, 16607 Prague 6, Czech Republic

${ }^{h}$ INFN Milano and Università di Milano, Dipartimento di Fisica,

Via Celoria 16, 20133 Milano, Italy

${ }^{i}$ B.P. Konstantinov Petersburg Nuclear Physics Institute (PNPI),

188300 St. Petersburg, Russia

${ }^{j}$ Rutherford Appleton Laboratory - Science \& Technology Facilities Council,

Harwell Science and Innovations Campus, Didcot OX11 OQX, United Kingdom

${ }^{k}$ Graduate School of Pure and Applied Sciences, University of Tsukuba,

1-1-1 Tennodai, Tsukuba, Ibaraki 305-8577, Japan

${ }^{l}$ Department of Mechanical Engineering - Thermal Energy and Air Conditioning Division,

Università degli Studi di Genova Via All'Opera Pia 15a - 16145 Genova, Italy

E-mail: gregh@cppm.in2p3.fr

\footnotetext{
${ }^{1}$ Corresponding author.
} 
ABSTRACT: We describe a combined ultrasonic instrument for gas flow metering and continuous real-time binary gas composition measurements. The combined flow measurement and mixture analysis algorithm employs sound velocity measurements in two directions in combination with measurements of the pressure and temperature of the process gas mixture.

The instrument has been developed in two geometries following extensive computational fluid dynamics studies of various mechanical layouts. A version with an axial sound path has been used with binary gas flows up to $2301 . \mathrm{min}^{-1}$, while a version with a sound path angled at $45^{\circ}$ to the gas flow direction has been developed for use in gas flows up to $200001 . \mathrm{min}^{-1}$.

The instrument with the axial geometry has demonstrated a flow resolution of $\leq 1 \%$ of full scale for flows up to $2301 . \mathrm{min}^{-1}$ and a mixture resolution of $3.10^{-3}$ for $\mathrm{C}_{3} \mathrm{~F}_{8} / \mathrm{C}_{2} \mathrm{~F}_{6}$ molar mixtures with $\sim 20 \% \mathrm{C}_{2} \mathrm{~F}_{6}$. Higher mixture precision is possible in mixtures of gases with widely-differing molecular weight (mw): a sensitivity of $<5.10^{-5}$ to traces of $\mathrm{C}_{3} \mathrm{~F}_{8}$ in nitrogen (mw difference 160 ) has been seen in a long duration ( $>1 \mathrm{yr}$ ) continuous study.

A prototype instrument with $45^{\circ}$ crossing angle has demonstrated a flow resolution of $1.9 \%$ of full scale for linear flow velocities up to $15 \mathrm{~ms}^{-1}$.

Although this development was motivated by a requirement of the ATLAS silicon tracker evaporative fluorocarbon cooling system, the developed instrument can be used in many applications where continuous knowledge of binary gas composition is required. Applications include the analysis of hydrocarbons, vapour mixtures for semi-conductor manufacture and anaesthetic gas mixtures.

KEYWORDS: Detector cooling and thermo-stabilization; Gas systems and purification; Materials for gaseous detectors

ARXIV EPRINT: 1210.4835 


\section{Contents}

1 Introduction 1

2 Principle of operation 4

3 Mechanics, fluid dynamics studies and measurements 6

3.1 "Pinched axial" geometry for analysis and flowmetry in gas flows up to $2501 . \mathrm{min}^{-1} \quad 6$

3.2 Angled crossing geometry for analysis and flowmetry at flows up to $200001 . \mathrm{min}^{-1} \quad 15$

4 Electronics $\quad 24$

5 Transducer inter-distance calibration and transit time uncertainty estimation 26

$\begin{array}{lll}6 & \text { SCADA and analysis software } & 27\end{array}$

$\begin{array}{llr}7 & \text { Conclusion } & 29\end{array}$

\section{Introduction}

The development of a combined flowmeter and binary gas analyzer is motivated by a possible future upgrade of the ATLAS silicon tracker evaporative cooling system, in which the currently-used octafluoro-propane fluorocarbon evaporative coolant $\left(\mathrm{R} 218, \mathrm{C}_{3} \mathrm{~F}_{8}\right.$; molecular weight $\left.=188\right)$ [1] will be blended with the more volatile hexafluoro-ethane $\left(\mathrm{R} 116, \mathrm{C}_{2} \mathrm{~F}_{6} ; \mathrm{mw}=138\right)$.

In the new instrument sound transit times will be continuously measured in opposite directions in flowing gas at known temperature and pressure to deduce the $\mathrm{C}_{3} \mathrm{~F}_{8} / \mathrm{C}_{2} \mathrm{~F}_{6}$ flow rate and mixture composition, the latter with a required precision of better than $\pm 1 \%$. The instrument - implemented with axial and angled sound path geometries following extensive Computational Fluid Dynamics (CFD) studies - is described in the following sections together with its electronics and Supervisory, Control and Data Acquisition (SCADA) software.

An evaporative coolant based on a $\mathrm{C}_{3} \mathrm{~F}_{8} / \mathrm{C}_{2} \mathrm{~F}_{6}$ mixture will afford the silicon substrates a better safety margin against leakage current-induced thermal runaway [2] caused by cumulative radiation damage as the LHC luminosity profile increases. The temperature of the silicon substrates of the ATLAS Semi Conductor Tracker (SCT) must be maintained at $-7^{\circ} \mathrm{C}$ or lower [3] while the ATLAS pixel detector modules must be maintained at $0^{\circ} \mathrm{C}$ or lower [4], being typically operated around $-10^{\circ} \mathrm{C}$.

At full power dissipation, thermal resistances through the support structures attaching the silicon modules to the coolant channels predicate a typical evaporation temperature of $\sim-25^{\circ} \mathrm{C}$ in the on-detector cooling channels of the $204 \mathrm{SCT}$ and pixel cooling circuits. With pure $\mathrm{C}_{3} \mathrm{~F}_{8}$ this temperature corresponds to an evaporation pressure of $1.7 \mathrm{bar}_{\text {abs. }}$. In the highest power cooling circuits (with a dissipation $\sim 288$ Watts - corresponding to $\sim 6 \mathrm{~W}$ per silicon detector module - 
Table 1. Evaporation pressures at $-25^{\circ} \mathrm{C}$ evaporation temperature in $\mathrm{C}_{3} \mathrm{~F}_{8}$ and several $\mathrm{C}_{3} \mathrm{~F}_{8} / \mathrm{C}_{2} \mathrm{~F}_{6}$ blends.

\begin{tabular}{|c|c|c|}
\hline $\begin{array}{c}\text { Fluorocarbon } \\
\text { Coolant }\end{array}$ & $\begin{array}{c}\text { Median (Minimum) Evaporation } \\
\text { pressure for evaporation at }-25^{\circ} \mathrm{C}\end{array}$ & $\begin{array}{c}\text { Sound velocity }\left(\mathrm{ms}^{-1}\right) \text { in superheated } \\
\text { vapour }\left(20^{\circ} \mathrm{C}, 1 \text { bar }_{\text {abs }}\right)\end{array}$ \\
\hline $\mathrm{C}_{3} \mathrm{~F}_{8}$ & $1.7(1.7) \mathrm{bar}_{\mathrm{abs}}$ & 115.0 \\
\hline $90 \% \mathrm{C}_{3} \mathrm{~F}_{8} / 10 \% \mathrm{C}_{2} \mathrm{~F}_{6}$ & $2.2(1.8) \mathrm{bar}_{\mathrm{abs}}$ & 116.8 \\
\hline $80 \% \mathrm{C}_{3} \mathrm{~F}_{8} / 20 \% \mathrm{C}_{2} \mathrm{~F}_{6}$ & $2.7(2.1) \mathrm{bar}_{\mathrm{abs}}$ & 118.7 \\
\hline $70 \% \mathrm{C}_{3} \mathrm{~F}_{8} / 30 \% \mathrm{C}_{2} \mathrm{~F}_{6}$ & $3.2(2.3) \mathrm{bar}_{\mathrm{abs}}$ & 120.7 \\
\hline
\end{tabular}

we are presently unable to achieve in-tube evaporation temperatures (pressures) below $\sim-16.5^{\circ} \mathrm{C}$ ( 2.3 bar $\left._{\text {abs }}\right)$ [2] due to excessive pressure drops (in the range 500-800 mbar, depending on power dissipation in the cooling circuit) in inaccessible regions of the exhaust vapour return system. The addition of the more volatile $\mathrm{C}_{2} \mathrm{~F}_{6}$ as part of a binary blend will raise the evaporation pressure for the same evaporation temperature - as indicated in table 1 - allowing the pressure drop in the exhaust to be overcome.

In table 1 the minimum and median evaporation pressures are those at which $100 \%$ and $50 \%$ of the injected refrigerant have been respectively transformed to vapour. In the ATLAS evaporative cooling system the coolant flow is fixed (typically to $\sim 120 \%$ of the flow necessary for simultaneous full power operation of all the silicon detector modules in the circuit) and a fraction of the coolant (dependent on the power dissipated in the silicon modules which constitute the "ondetector" evaporator) is evaporated in electrically-powered heaters in the exhaust system (see [1] for more details). The minimum pressures shown in table 1 correspond to those at the outputs of those heaters.

In operation with $\mathrm{C}_{3} \mathrm{~F}_{8} / \mathrm{C}_{2} \mathrm{~F}_{6}$ blends it will be necessary to monitor the $\mathrm{C}_{3} \mathrm{~F}_{8} / \mathrm{C}_{2} \mathrm{~F}_{6}$ mixture ratio to a precision of $1 \%$ or better and if necessary to adjust it with the addition of more of either component. The mixture ratio is best monitored in the warm region of the vapour return tubing (far from the on-detector evaporative cooling channels) where the vapour mixture is in the superheated (single phase) state, simplifying sound velocity predictions. In table 1 the sound velocities at $20^{\circ} \mathrm{C}$, $1 \mathrm{bar}_{\text {abs }}$, calculated using the NIST-REFPROP package [5] are shown as examples.

Additionally, the present underground compressor-driven $\mathrm{C}_{3} \mathrm{~F}_{8}$ circulation plant will be replaced by a thermosiphon equipped with a surface-mounted condenser, allowing the $\sim 90 \mathrm{~m}$ depth of the ATLAS experimental cavern to be exploited to hydrostatically generate the required fluorocarbon liquid delivery pressure. A combined mixture analyzer/flow meter will be installed in the superheated vapour return to the surface condenser, where a high flow of $\sim 200001 . \mathrm{min}^{-1}$ is expected. An ultrasonic gas mixture analyzer will also monitor for un-condensable gas (air) ingress into the sub-atmospheric vapour (headspace) volume of the surface condenser.

The sound velocity in a binary gas mixture at known temperature and pressure is a unique function of the molar concentration of the two components of differing molecular weight. Ultrasonic binary gas analysis was first used in particle physics for the analysis of the $\mathrm{N}_{2} / \mathrm{C}_{5} \mathrm{~F}_{12}$ (dodecafluoropentane: $\mathrm{mw}=288$ ) Cherenkov gas radiator of the SLD Cherenkov Ring Imaging Detector [6], as a simpler alternative to on-line refractive index monitoring. Since then it has been adopted in all the major ring imaging Cherenkov detectors, including DELPHI, COMPASS and LHCb. 
The molar concentration of the two component vapours is determined from a comparison of sound velocity measurements with velocity-composition look-up table data gathered from prior measurements in calibration mixtures or from theoretical derivations made with an appropriate equation of state. The NIST-REFPROP package [5] is based on the most accurate pure fluid and mixture models currently available for a wide range of fluid combinations. It currently implements three models for the thermodynamic properties of pure fluids: equations of state explicit in Helmholtz energy, the modified Benedict-Webb-Rubin (BWR) equation of state, and an extended corresponding states (ECS) model. Mixture calculations employ a model that applies mixing rules to the Helmholtz energy of the mixture components [5]. NIST-REFPROP is presently the optimum for calculating sound velocity in fluorocarbon mixtures - including those containing $\mathrm{C}_{2} \mathrm{~F}_{6}$ and $\mathrm{C}_{3} \mathrm{~F}_{8}$. It is not, however configured for calculations in mixtures of fluorocarbons with other gases - including $\mathrm{N}_{2} / \mathrm{C}_{3} \mathrm{~F}_{8}$; a combination also of interest in this work in the detection of leaks of the present $\mathrm{C}_{3} \mathrm{~F}_{8}$ evaporative coolant into the ATLAS silicon tracker nitrogen gas envelope. Sound velocity predictions in $\mathrm{N}_{2} / \mathrm{C}_{3} \mathrm{~F}_{8}$ mixtures were made using a PC-SAFT ${ }^{1}$ equation of state [7]. Sound velocity predictions made with the NIST-REFPROP and PC-SAFT approaches are compared with measurements in section 3.1.

Figure 1 illustrates the variation of sound velocity with molecular weight for a variety of families of gases, including the monatomic (noble) gases, gases with di-atomic molecules, including oxygen $\left(\mathrm{O}_{2}\right)$ and nitrogen $\left(\mathrm{N}_{2}\right)$, tri-atomic gases including carbon dioxide $\left(\mathrm{CO}_{2}\right)$ and hydrocarbons of the alkane $\left(\mathrm{C}_{n} \mathrm{H}_{(2 n+2)}\right)$ and alkene $\left(\mathrm{C}_{n} \mathrm{H}_{(2 n)}\right)$ families. Also shown are the members of the saturated fluorocarbon $\left(\mathrm{C}_{n} \mathrm{~F}_{(2 n+2)}\right)$ family of vapours used in particle physics as Cherenkov radiators and evaporative coolants for silicon tracking detectors.

It can be seen from figure 1 that the $\log$ sound velocity - log molecular weight zone is bounded by two parallel limits. The upper limit represents the monatomic gases with $\gamma$, [the ratio of specific heat at constant pressure to that at constant volume $\left.\left(\mathrm{C}_{p} / \mathrm{C}_{v}\right)\right]=1.66$. The noble gases lie along this limit. The lower limit is defined by $\gamma=1$. Gases with progressively more complex chained molecules tend toward the lower limit. It can be seen from figure 1 that while the log sound velocity - $\log$ molecular weight trajectory follows an index of -0.5 for the noble gases, the index steepens for more complex molecular shapes. This is a manifestation of their deviation from a simple ideal gas formulation of sound velocity, c, defined by;

$$
c=\sqrt{\frac{\gamma R T}{m}}
$$

where $R$ is the molar gas constant $\left(8.314 \mathrm{~J} \cdot \mathrm{mole}^{-1} \mathrm{~K}^{-1}\right), T$ is the absolute temperature (K) and $m$ is the molar weight (expressed in $\mathrm{kg}$ ) - toward more complex formalisms based on more sophisticated equations of state. The "non-ideality" of a gas group is manifested through the variation (decrease) of $\gamma$ with (increasing) molecular weight, under conditions of equivalent temperature and pressure.

Within the ATLAS experiment the new instrument has been used for flowmetry and mixture analysis of $\mathrm{C}_{3} \mathrm{~F}_{8} / \mathrm{C}_{2} \mathrm{~F}_{6}$ blends and also as a sensitive detector of leaks of the present $\mathrm{C}_{3} \mathrm{~F}_{8}$ evaporative coolant into the silicon tracker nitrogen gas envelope. The instrument is described along with test results in the following sections.

\footnotetext{
${ }^{1}$ Perturbed Chain — Statistical Associating Fluid Theory.
} 


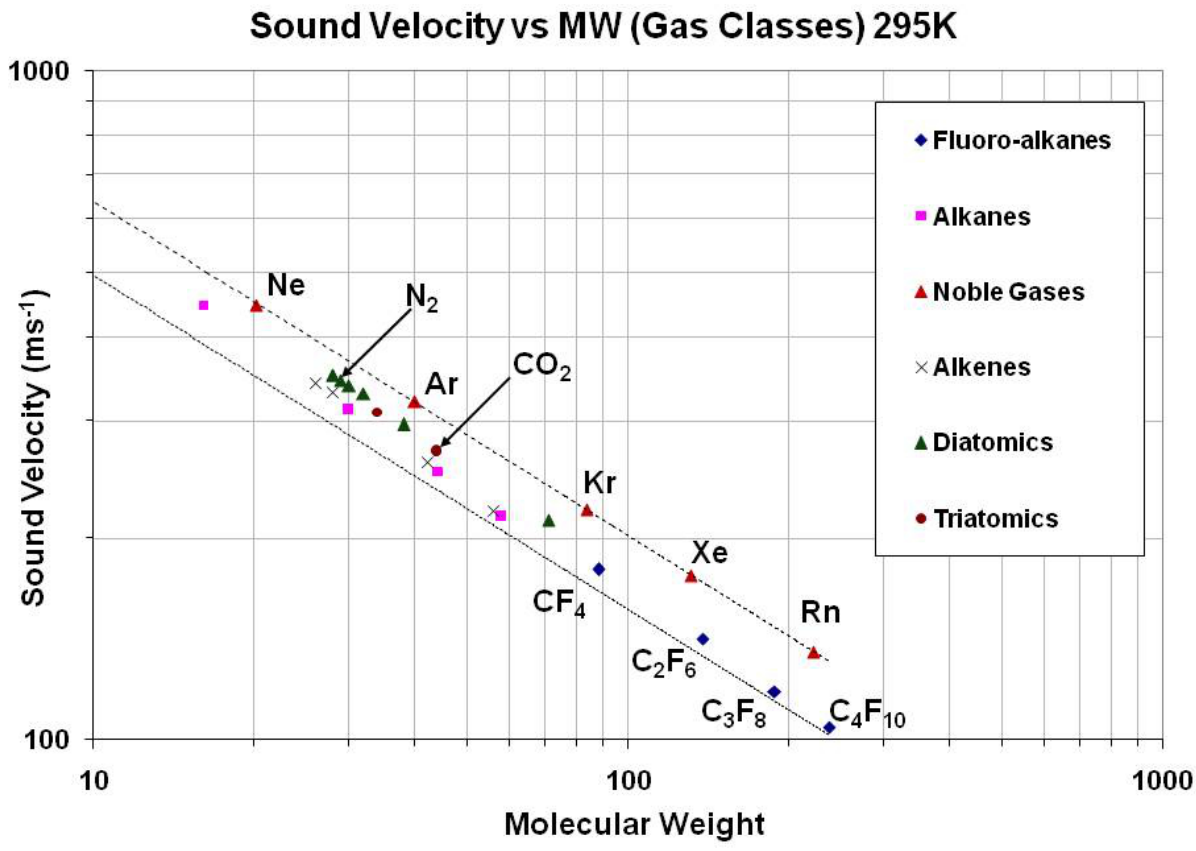

Figure 1. Variation of sound velocity with molecular weight for a variety of families of gases, at temperature $295 \mathrm{~K}$ and pressure 1 bar $_{\mathrm{abs}}$.

\section{Principle of operation}

Figure 2 illustrates the principle of operation of the instrument. In custom microcontroller-based electronics (section 4), the transmitting transducer is excited with a short burst of 1-8 high voltage $50 \mathrm{kHz}$ square wave pulses generated in a driver circuit from a TTL precursor pulse train, itself generated in the microcontroller. The receiving transducer is connected to a DC biasing circuit followed by an amplifier and comparator. A fast $(40 \mathrm{MHz})$ transit time clock, generated in the same microcontroller, is started in synchronism with the rising edge of the first transmitted $50 \mathrm{kHz}$ sound pulse. The first received and amplified sound pulse crossing the comparator threshold level stops this clock (figure 2). The time between the transmitted and first received sound pulses is measured by the microcontroller, which also handles communication via a USB/RS232 interface.

Figure 3 illustrates the $50 \mathrm{kHz}$ capacitative ultrasonic transducer, originally developed during the 1980s for the Polaroid autofocus instant camera and now marketed by SensComp as the Model 604142 instrument grade transducer. The transducer has a diameter of $42.9 \mathrm{~mm}$ and comprises a gold coated mylar foil stretched over a metallic backing plate etched with a spiral groove. The backing plate is biased and excited at a high voltage $(80-360 \mathrm{~V})$ with the case and foil grounded. Although the transducer was originally developed for operation in air at ambient temperature and atmospheric pressure, the spiral groove allows gas to access both sides of the diaphragm, allowing operation over a wide pressure range. We have tested and operated these transducers in non corrosive gases at pressures ranging from $5 \mathrm{bar}_{\text {abs }}$ to sub-atmospheric pressures of around 100 mbar $_{\text {abs }}$ and temperatures in the range -30 to $+45^{\circ} \mathrm{C}$.

In the custom electronics sound bursts are sent in opposite directions which may be aligned with - or at an angle to - the gas flow. Rolling average transit times, temperature and pressure 


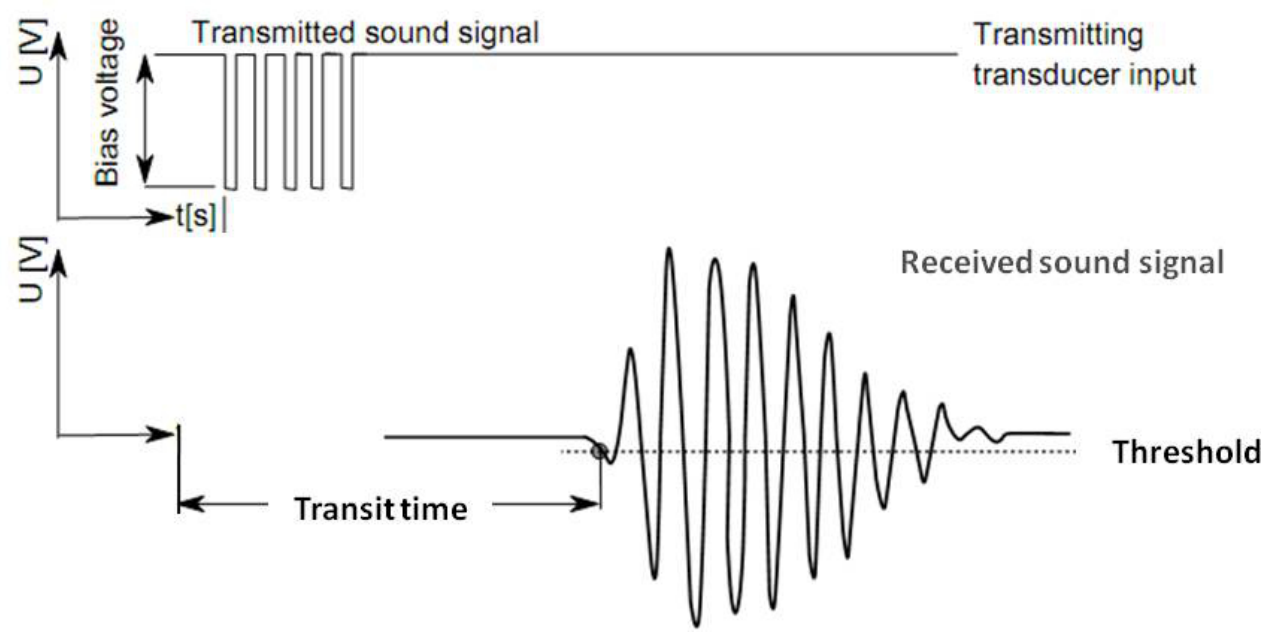

Figure 2. Principle of measurement of transit time between the first transmitted sound pulse and the first over-threshold detected pulse.

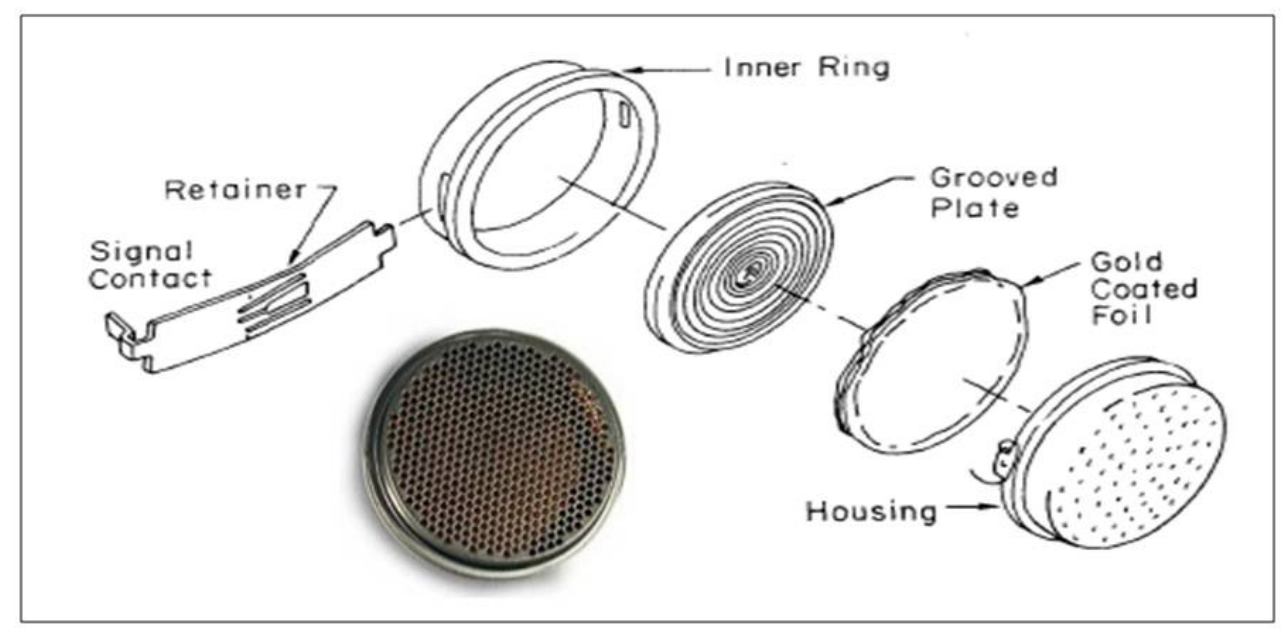

Figure 3. The SensComp $50 \mathrm{kHz}$ capacitative ultrasonic transducer, originally developed during the 1980s for the Polaroid autofocus instant camera.

data continually stream from a FIFO memory to a supervisory computer presently via RS232 or USB, and in the future also by CANbus or Ethernet.

The gas mixture and flow rate are continuously calculated using SCADA software implemented in PVSS-II [8]. Transit times in both directions are used to compute the gas flow rate while the averages of the sound velocities in the two directions are used together with temperature and pressure to compute the binary gas composition by comparison with stored velocity vs. concentration look-up tables (section 6). These tables may be created from prior measurements in calibration mixtures or from theoretical thermodynamic calculations. In future versions of the instrument these calculations may be made in an on-board microcontroller. 


\section{Mechanics, fluid dynamics studies and measurements}

The instrument has been constructed and evaluated in two distinct geometries:

(i) with an axial sound path: used as a combined gas mixture analyzer/in line flow meter for fluorocarbon gas flows up to $2501 . \mathrm{min}^{-1}$ and as a $\mathrm{C}_{3} \mathrm{~F}_{8}$ leak analyzer at sampling rates of around $100 \mathrm{ml} . \mathrm{min}^{-1}$;

(ii) with an angled crossing sound path: a geometry required for fluorocarbon flows around $1.2 \mathrm{kgs}^{-1}$. Such vapour mass flows are equivalent to volume flow of $\sim 200001 . \mathrm{min}^{-1}$ in $70 \% \mathrm{C}_{3} \mathrm{~F}_{8} / 30 \% \mathrm{C}_{2} \mathrm{~F}_{6}$ (density $3.58 \mathrm{kgm}^{-3}$ ) or $\sim 184001 . \mathrm{min}^{-1}$ in pure $\mathrm{C}_{3} \mathrm{~F}_{8}$ : (density $\left.3.90 \mathrm{kgm}^{-3}\right)$ in temperature and pressure conditions $\left(20{ }^{\circ} \mathrm{C}, 500 \mathrm{mbar}_{\mathrm{abs}}\right)$ characteristic of the superheated vapour return in the future ATLAS thermosiphon installation [9].

These implementations are described in the following sections.

\section{1 "Pinched axial" geometry for analysis and flowmetry in gas flows up to $2501 . \mathrm{min}^{-1}$}

The mechanical envelope and ultrasonic transducer mounting are illustrated in figure 4 . The transducers are mounted around $666 \mathrm{~mm}$ apart in a flanged assembly made from cold-rolled seamlesss 304L stainless steel tube with overall length $\sim 850 \mathrm{~mm}$. The temperature in the tube is monitored by six NTC thermistors - $\left(100 \mathrm{k} \Omega\right.$ at $\left.25^{\circ} \mathrm{C}\right)$ - giving an average temperature measurement uncertainty of better than $\pm 0.3^{\circ} \mathrm{C}$. Pressure is monitored with a transducer having \pm 1 mbar precision.

The transducers are centered and mounted flush with the inboard ends of wide bore sections of tube, between which are welded a pair of diameter reducing cones and a 'pinched' region (of inner diameter $44.3 \mathrm{~mm}$, compared with the transducer diameter of $42.9 \mathrm{~mm}$ ) through which all the vapour is channelled. Vapour is diverted around the ultrasonic transducers through the use of $5 \mathrm{~cm}$ long axial flow-deflecting cones machined from PEEK $\AA$.

In this simple geometry the vapour flow rate is calculated from the sound transit times measured parallel, $\mathrm{t}_{\mathrm{down}}$, and anti-parallel, $\mathrm{t}_{\mathrm{up}}$, to the flow direction, according to the following algorithm:

$$
t_{\text {down }}=\frac{L}{(c+v)}, \quad t_{\text {up }}=\frac{L}{(c-v)}
$$

where $v$ is the linear flow velocity, $\left(\mathrm{ms}^{-1}\right), c$ is the sound velocity in the gas $\left(\mathrm{ms}^{-1}\right)$ and $L$ is the distance $(\mathrm{m})$ between transducers.

The gas volume flow $\mathrm{V}\left(\mathrm{m}^{3} \mathrm{~s}^{-1}\right)$ can then be inferred from the two transit times by:

$$
V=\frac{L \cdot A\left(t_{\text {up }}-t_{\text {down }}\right)}{2\left(t_{\text {up }} \cdot t_{\text {down }}\right)}
$$

where $\mathrm{A}$ is the internal cross sectional area of the axial flow tube between the ultrasonic transducers $\left(\mathrm{m}^{2}\right)$.

The sound velocity can also be inferred from the two transit times via:

$$
c=\frac{L\left(t_{\text {up }}+t_{\text {down }}\right)}{2\left(t_{\text {up }} \cdot t_{\text {down }}\right)}
$$




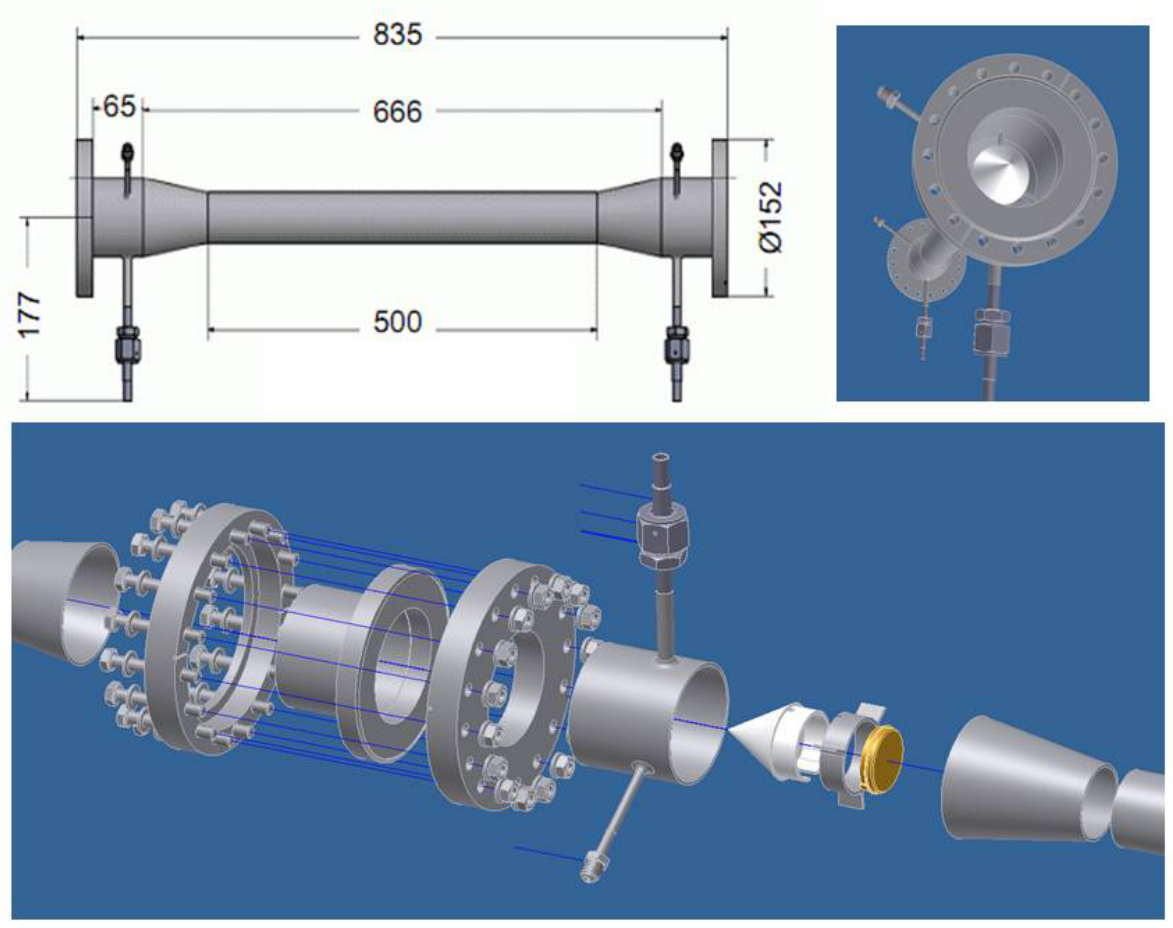

Figure 4. The 'pinched axial' mechanical envelope, showing an ultrasonic transducer, its mounting and axial flow-deflecting cone, together with tubes for pressure sensing and the evacuation and the injection of calibration gas.

It can be seen from eqs. (3.1)-(3.3) that knowledge of the temperature of the gas is not necessary for ultrasonic flowmetry alone.

Three such instruments have been constructed for studies of $\mathrm{C}_{2} \mathrm{~F}_{6} / \mathrm{C}_{3} \mathrm{~F}_{8}$ blends. Figure 5 illustrates one of these instruments installed in the ATLAS $\mathrm{C}_{2} \mathrm{~F}_{6} / \mathrm{C}_{3} \mathrm{~F}_{8}$ blend development recirculator. The oil-less piston compressor of the recirculator is shown in the left foreground.

The upper plots of figure 6 show the linearity of the ultrasonic flow meter element of the instrument in $\mathrm{C}_{3} \mathrm{~F}_{8}$ vapour at $20^{\circ} \mathrm{C}$ and 1 bar $_{\text {abs }}\left(\mathrm{C}_{3} \mathrm{~F}_{8}\right.$ density $\left.\sim 7.9 \mathrm{kgm}^{-3}\right)$ through comparison with a mass flow meter ${ }^{2}$ and with a volumetric gas meter ${ }^{3}$ at flows up to a maximum of $2301 . \mathrm{min}^{-1}$; the limiting flow in the presently-available $\mathrm{C}_{3} \mathrm{~F}_{8} / \mathrm{C}_{2} \mathrm{~F}_{6}$ blend recirculator. At flows above $1501 . \mathrm{min}^{-1}$ it was noted that the internal rotating piston mechanics of the gas meter became very noisy, having been drained of the normal lubricant charge to avoid contaminating the oil-less compressor of the recirculator.

The horizontal error bars on the two sets of flow data points in the upper plots of figure 6 represent the quoted precisions of the respective comparison instruments. These are also represented in the lower plot of figure 6 as vertical error bars on the points representing the difference in flow measured between the ultrasonic flowmeter and the reference instruments. The uncertainties attributable to the ultrasonic flowmeter - shown as vertical error bars in the two flow comparison plots in the upper plots of figure 6 - reflect the combination of the uncertainty in the main tube

\footnotetext{
${ }^{2}$ Bronkhorst F-113AI-AAD-99-V; full scale $1001 . \mathrm{min}^{-1} \mathrm{C}_{3} \mathrm{~F}_{8}$; precision: $\pm 0.8 \%$ of reading plus $\pm 0.2 \%$ full scale.

${ }^{3}$ Schlumberger Delta G16: maximum flow rate $4171 . \mathrm{min}^{-1}$, precision $\pm 1 \%$ of full scale.
} 


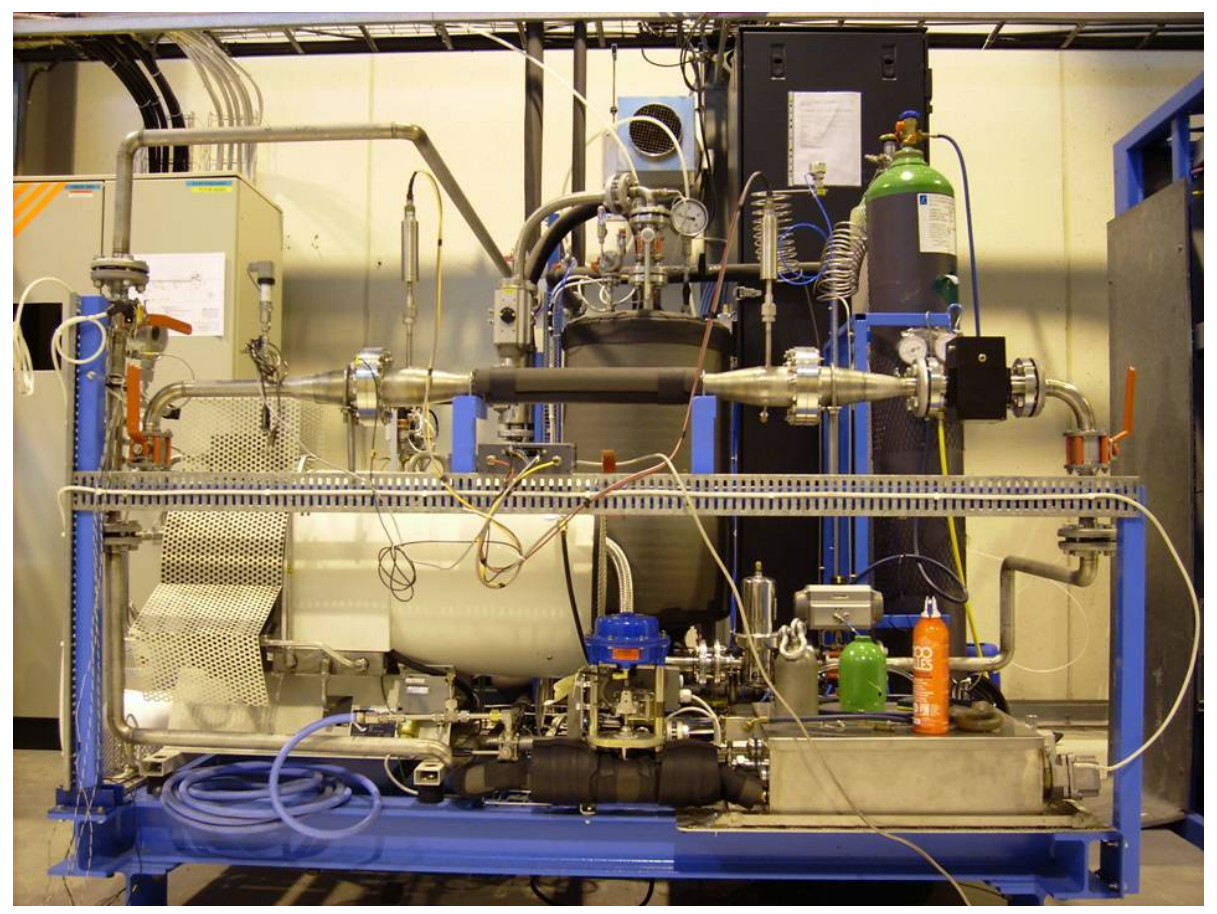

Figure 5. 'Pinched axial' geometry analyzer/flow meter installed in the ATLAS $\mathrm{C}_{2} \mathrm{~F}_{6} / \mathrm{C}_{3} \mathrm{~F}_{8}$ blend, recirculator followed by a Schlumberger Delta G16 integrating gas meter (right foreground).

diameter $( \pm 0.5 \mathrm{~mm})$, timing precision $( \pm 100 \mathrm{~ns}$, as discussed in section 4$)$ and transducer spacing $( \pm 0.1 \mathrm{~mm}$ following length calibration in a quasi-ideal static gas, according to the procedure discussed in section 5). A tube diameter uncertainty of $\pm 0.5 \mathrm{~mm}$ would represent the dominant error: an uncertainty of $\pm 2.2 \%$ of flow value. However this is probable overestimate based on the maximum local diameter tolerance quoted by the tube manufacturer: the diameter of the central tube would be very unlikely to have such a constant deviation from the nominal diameter over the whole length of $50 \mathrm{~cm}$.

The rms deviation of the ultrasonic flowmeter relative to the fit with the Schlumberger gas meter is $\pm 2.31 . \mathrm{min}^{-1}$ (around $1.0 \%$ of the limiting flow of $2301 . \mathrm{min}^{-1}$ ) while that relative to the Bronkhorst flowmeter is $\pm 0.241 . \mathrm{min}^{-1}$, around $0.27 \%$ of the maximum flow of $901 . \mathrm{min}^{-1}$ reached in the comparison of the two instruments.

A Computational Fluid Dynamics (CFD) study was undertaken using the OpenFOAM $₫$ package [10] with the SST k- $\omega$ [11] turbulence model and a mesh of 545000 polyhedral cells, in order to evaluate the likely effect of the ultrasonic transducers, flow deflection and diameter reduction cones on the measurement precision. "Start condition" volume flows of 100 and $2001 . \mathrm{min}^{-1}$ of $\mathrm{C}_{3} \mathrm{~F}_{8}$ at $1 \mathrm{bar}_{\text {abs }}$ and $20^{\circ} \mathrm{C}$ (density $\sim 7.9 \mathrm{kgm}^{-3}$ ), corresponded to transversally-averaged axial flow velocities of 1.08 and $2.16 \mathrm{~ms}^{-1}$ in the $44.3 \mathrm{~mm}$ ID "pinched" tube linking the transducers. The average velocity along the $666 \mathrm{~mm}$ axis between the centres of the two transducer disks covering the full acoustic path including the centre pinched tube and the two conical regions was estimated by CFD simulation. The CFD calculations, shown in figures 7 and 8 and in table 2, suggest a 9\% deficit compared with the flow averaged across the whole cross section of the pinched 


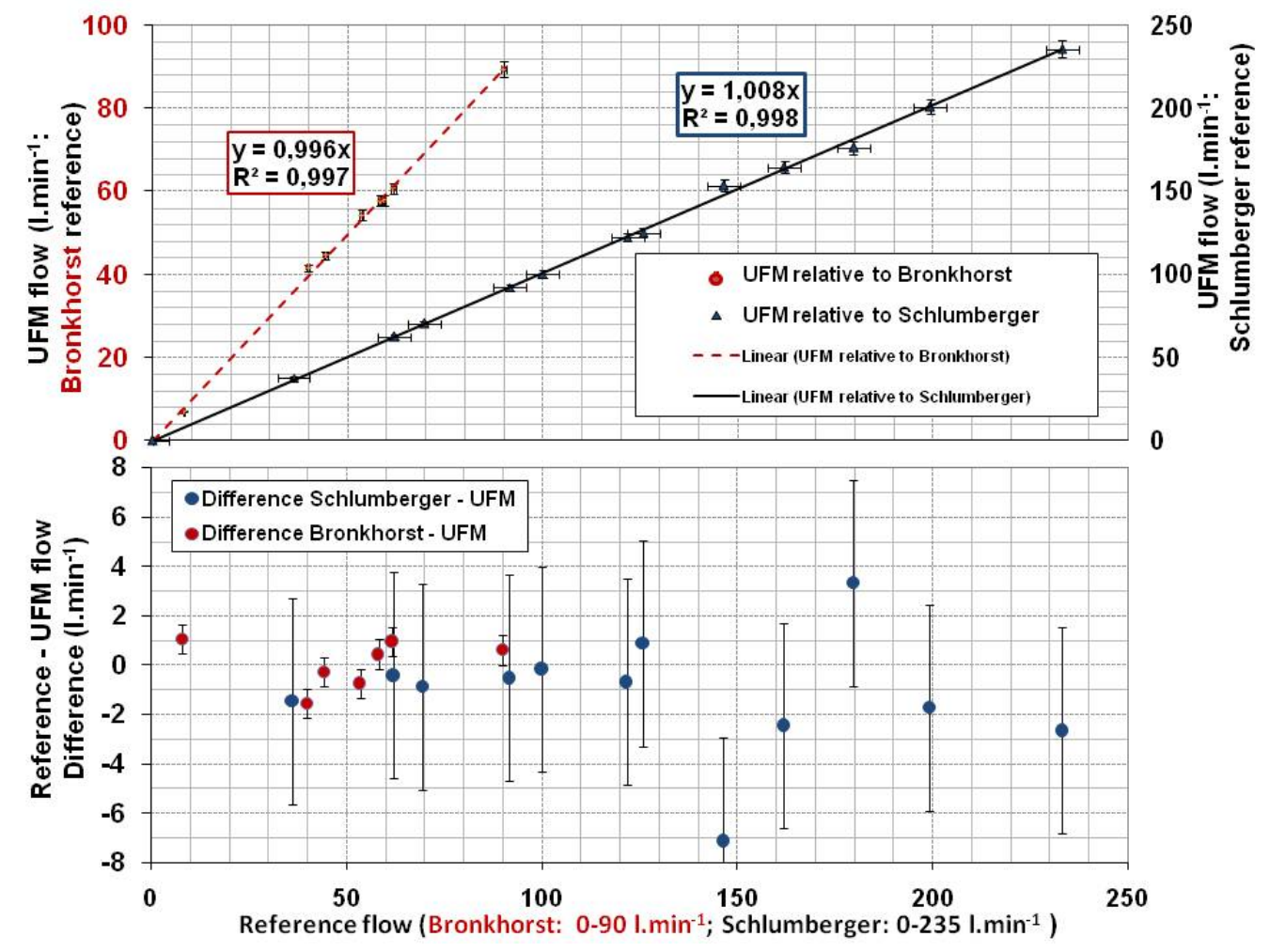

Figure 6. Upper plot: 'pinched axial' ultrasonic flow meter comparisons with a Schlumberger Delta G16 gas and a Bronkhorst F-113AI-AAD-99-V mass flow meter in $\mathrm{C}_{3} \mathrm{~F}_{8}$ vapour at 1 bar $_{\text {abs }}$ and $20^{\circ} \mathrm{C}$ (density $\sim 7.9$ $\mathrm{kgm}^{-3}$ ). Lower plot: differences between flow measurements in the ultrasonic flowmeter and the reference instruments.

Table 2. "Pinched Axial" flowmeter: comparison of the average velocity in the $44.3 \mathrm{~mm}$ "pinch" tube with the CFD-calculated average velocity along the axis linking the centres of the two transducers.

\begin{tabular}{|c|c|c|c|}
\hline $\begin{array}{c}\text { Starting } \\
\text { flow rate } \\
\left(1 . \mathrm{min}^{-1}\right)\end{array}$ & $\begin{array}{c}\text { Expected average flow } \\
\text { velocity in } 44.3 \mathrm{~mm} \text { ID } \\
\text { 'pinch' tube }\left(\mathrm{ms}^{-1}\right)\end{array}$ & $\begin{array}{c}\text { CFD average velocity } \\
\text { along axis linking } \\
\text { transducer centres }\left(\mathrm{ms}^{-1}\right)\end{array}$ & $\begin{array}{c}\text { Difference between flow } \\
\text { velocity along tube axis } \\
\text { and average velocity (\%) }\end{array}$ \\
\hline 100 & 1.08 & 0.983 & -9.14 \\
\hline 200 & 2.16 & 1.95 & -9.65 \\
\hline
\end{tabular}

tube, due to:

- a vortex trailing the upstream ultrasonic transducer within the $83 \mathrm{~mm}$ upstream reduction cone (figure 4) where the tube inner diameter shrinks from $72.1 \mathrm{~mm}$ to $44.3 \mathrm{~mm}$;

- the slab-like obstruction of the downstream transducer, in front of which the vapour is axially decelerated, then swept transversely to leave the acoustic sensing volume.

The CFD results of figure 8 and table 2 show the on-axis flow velocity deficit to be fairly constant with flow rate, suggesting that linear calibration against other instrumentation should be possible, as independently demonstrated in figure 6. A transverse profile shows the effect of the 


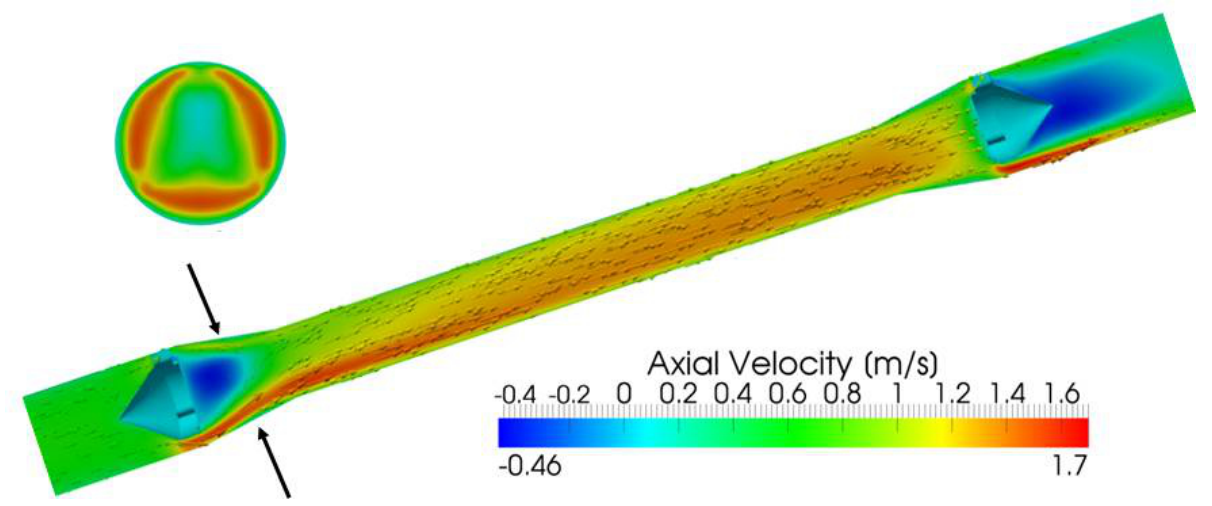

Figure 7. Stream lines and contours of the axial component of gas flow velocity $\left(\mathrm{ms}^{-1}\right)$ in a longitudinal cut along the tube. Inset a transverse cut showing the higher axial flow zones immediately following the upstream transducer on its $120^{\circ}$ 3-point mounting (also shown in figure 4).
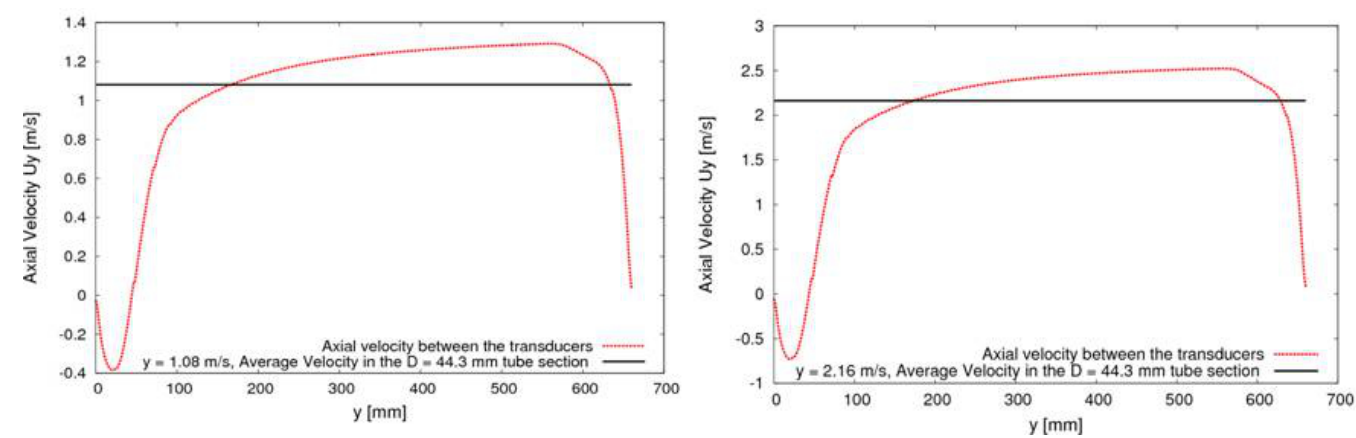

Figure 8. Axial flow velocity $\left(\mathrm{C}_{3} \mathrm{~F}_{8}\right.$ at $\left.1 \mathrm{bar}_{\mathrm{abs}}, 20^{\circ} \mathrm{C}\right)$ along the $666 \mathrm{~mm}$ central axis between the ultrasonic transducers. The average velocities in the $44.3 \mathrm{~mm}$ diameter tube of $1.08 \mathrm{~ms}^{-1}$ (left plot) and $2.16 \mathrm{~ms}^{-1}$ (right plot) respectively correspond to volume flow rates of 100 and $2001 . \mathrm{min}^{-1}$.

three-point transducer support on the flow in the annular passage around the transducer and downstream of it, giving rise to three zones of high axial velocity near the tube wall. Since the inner diameter of the pinched tube is well matched to that of the transducers, the higher velocity zones compensate the perceived loss along the axis.

Figure 9 illustrates the sound velocity measured in the instrument in varying $\mathrm{C}_{2} \mathrm{~F}_{6} / \mathrm{C}_{3} \mathrm{~F}_{8}$ molar mixing ratios at a temperature of $19.2{ }^{\circ} \mathrm{C}$ and a pressure of 1.14 bar $_{\text {abs. }}$ The sound velocity predictions of the NIST-REFPROP and PC-SAFT formalisms are also plotted. For comparison, their respective differences from the measurements are plotted on a secondary axis.

The mixtures of $\mathrm{C}_{3} \mathrm{~F}_{8}$ and $\mathrm{C}_{2} \mathrm{~F}_{6}$ shown in figure 9 span the region of thermodynamic interest to the ATLAS silicon tracker cooling application and were set up by partial pressure ratio in the previously-evacuated tube, to create molar mixtures. Component partial pressures were set using a MKS "Baratron" capacitative absolute pressure gauge with a precision of \pm 1 mbar. The transducer foil inter-distance had been previously established using the gas calibration procedure described in section 5 , to a precision of $\pm 0.1 \mathrm{~mm}$.

Individual contributions (shown in parentheses below) to the overall $0.05 \mathrm{~ms}^{-1}$ sound velocity measurement error, $\partial c$, (equivalent to $0.042 \%$ at $20 \% \mathrm{C}_{2} \mathrm{~F}_{6}$ concentration) were due to: 


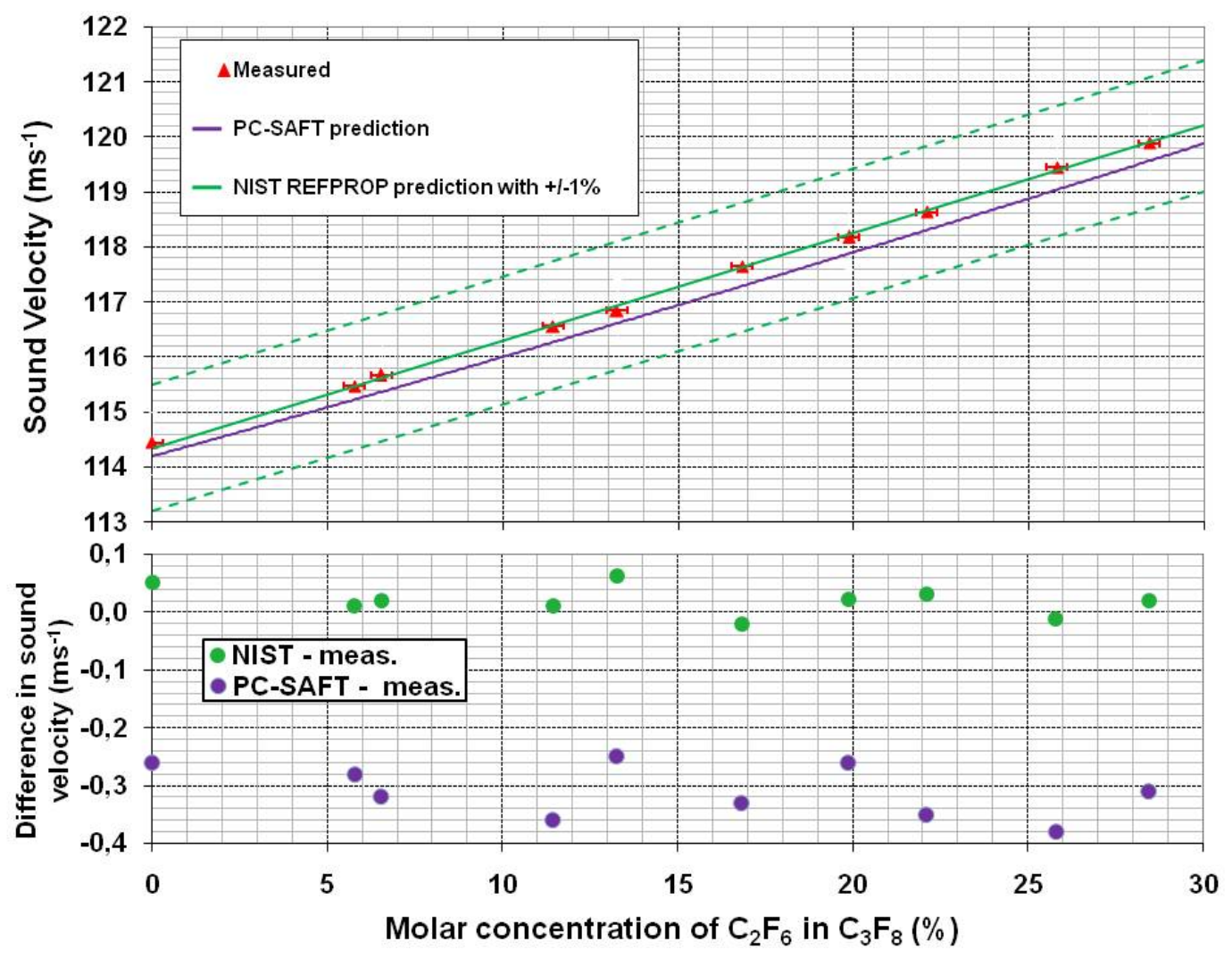

Figure 9. Upper plots: comparison between measured sound velocity data and theoretical predictions in molar $\mathrm{C}_{3} \mathrm{~F}_{8} / \mathrm{C}_{2} \mathrm{~F}_{6}$ mixtures of thermodynamic interest, at 1.14 bar $_{\text {abs }}$ and $19.2^{\circ} \mathrm{C}$. NIST-REFPROP sound velocity predictions shown within $\pm 1 \%$ band, after [12]. The binary gas mixture uncertainty of $0.3 \%$ is illustrated in red. Lower plots: differences between the measurements and the NIST-REFPROP and PCSAFT predictions.

- $\pm 0.2^{\circ} \mathrm{C}$ temperature stability in the sonar tube (equivalent to $\pm 0.044 \mathrm{~ms}^{-1}$ );

- \pm 4 mbar pressure stability in the sonar tube $\left( \pm 0.012 \mathrm{~ms}^{-1}\right)$ with blend circulation machine in operation;

- $\pm 0.1 \mathrm{~mm}$ transducer inter-foil measurement uncertainty $\left( \pm 0.018 \mathrm{~ms}^{-1}\right)$;

- $\pm 100 \mathrm{~ns}$ electronic transit time measurement uncertainty $\left( \pm 0.002 \mathrm{~ms}^{-1}\right)$.

The 16-bit precision of the analog input electronics results in an intrinsic accuracy 10-20 times finer than the operational stabilities in temperature and pressure quoted above.

The average difference between measured and the NIST-REFPROP [5] and PC-SAFT [7] predicted sound velocities in mixtures with $(0 \rightarrow 30 \%) \mathrm{C}_{2} \mathrm{~F}_{6}$ in $\mathrm{C}_{3} \mathrm{~F}_{8}$ were around $0.03 \%$ and $0.3 \%$ respectively at pressures around $1 \mathrm{bar}_{\mathrm{abs}}$ and temperatures around $19^{\circ} \mathrm{C}$. It is recognized that the present version of NIST-REFPROP [5] is more mature than the PC-SAFT equation of state and is thus the more precise in predicting the thermophysical properties of mixtures of saturated fluorocarbons (having molecular structures of the form $\mathrm{C}_{n} \mathrm{~F}_{(2 n+2)}$ ). 
The precision of mixture determination, $\partial(\mathrm{mix})$, at any concentration of the two components is given by;

$$
\partial(\operatorname{mix})=\frac{\partial c}{m}
$$

where $m$ is the local slope of the sound velocity/ concentration curve and $\partial c$ is the uncertainty in the sound velocity measurement. For example, in a blend of $20 \% \mathrm{C}_{2} \mathrm{~F}_{6}$ in $\mathrm{C}_{3} \mathrm{~F}_{8}$ - the sound velocity uncertainty of $0.05 \mathrm{~ms}^{-1}$ yields a concentration uncertainty $\sim 0.3 \%$ at $20 \% \mathrm{C}_{2} \mathrm{~F}_{6}$, where the slope of the sound velocity/ concentration curve is $\sim 0.18 \mathrm{~ms}^{-1} \%{ }^{-1}$.

The precision of the sound velocity determinations of the NIST-REFPROP package [5] for $\mathrm{C}_{2} \mathrm{~F}_{6}$ and $\mathrm{C}_{3} \mathrm{~F}_{8}$ has been independently estimated in [12], as part of an extensive set of comparisons between calculated thermodynamic and thermophysical parameters and measurement data from a large number of source references for 20 refrigerant fluids. The NIST-REFPROP determinations of sound velocity in $\mathrm{C}_{2} \mathrm{~F}_{6}\left(\mathrm{C}_{3} \mathrm{~F}_{8}\right)$ superheated vapour over the temperature \& pressure ranges 210 $475 \mathrm{~K} \& 0.8-32$ bar $_{\text {abs }}\left(245-342 \mathrm{~K} \& 0.1-16.2\right.$ bar $_{a b s}$ ), based respectively on the thermodynamic measurement data of 17 and 13 groups, were compared with sound velocity measurements made for each vapour by 2 groups. In the case of $\mathrm{C}_{3} \mathrm{~F}_{8}$ the average deviation was around $1 \%$, while for $\mathrm{C}_{2} \mathrm{~F}_{6}$ the average deviation was around $0.2 \%$. No comparisons have made between sound velocity measurements and predictions from NIST-REFPROP or PC-SAFT for $\mathrm{C}_{2} \mathrm{~F}_{6} / \mathrm{C}_{3} \mathrm{~F}_{8}$ molar mixtures until this work. Since $\mathrm{C}_{3} \mathrm{~F}_{8}$ is the dominant component in the mixture figure 9 illustrates the $1 \%$ sound velocity band (in green) from [12]. Clearly NIST-REFPROP sound velocity predictions are very much closer to our measurements than this. Indeed, figure 9 illustrates the present maturity of NIST-REPROP for the category of saturated fluorocarbons. In the case of our measurements we show the $0.3 \%$ mixture uncertainty (horizontal red error bars) coming from our sound velocity measurement uncertainty of $0.05 \mathrm{~ms}^{-1}$. We do not show error bars for PC-SAFT predicted sound velocities although it seems that the $\sim 0.3 \mathrm{~ms}^{-1}(\sim 0.3 \%)$ average difference with our measurements is likely to reflect that uncertainty given the present level of maturity of this equation of state.

In a second application related to the ATLAS evaporative cooling system, we use ultrasonic binary gas analysis to detect low levels of $\mathrm{C}_{3} \mathrm{~F}_{8}$ vapour leaking into the $\mathrm{N}_{2}$ environmental gas surrounding the ATLAS pixel tracker. Gas is aspirated from the pixel tracker volume through an ultrasonic analysis tube with a vacuum pump. A low flow of around $100 \mathrm{ml} . \mathrm{min}^{-1}$ is achievable through the (150 m long, $8 \mathrm{~mm}$ inner diameter) aspiration tube, with the analyzer tube operating at a pressure of 985 mbar $_{a b s} \pm 2$ mbar. Exhaust gas from the analysis tube (typically containing $>$ $99.9 \% \mathrm{~N}_{2}$ ) is vented to an air extraction system for return to the surface. The analyzer has been in continuous operation since January 2010, and is located - together with its data acquisition and supervisory computer - in a subterranean technical cavern alongside the ATLAS experimental cavern, whose floor is $92 \mathrm{~m}$ below the surface. A future expansion to this system will allow the envelope gases of the ATLAS silicon microstrip tracker (SCT) and inner detector volumes to be monitored. Additional analysis tubes are foreseen, together with full automation of gas stream selection.

Figure 10 compares measured sound velocities in molar concentrations of up to $10 \% \mathrm{C}_{3} \mathrm{~F}_{8}$ in $\mathrm{N}_{2}$ with sound velocity predictions from the PC-SAFT equation of state [7]. The data of figure 10 are abstracted from measurements and predictions made over the full concentration range from pure 


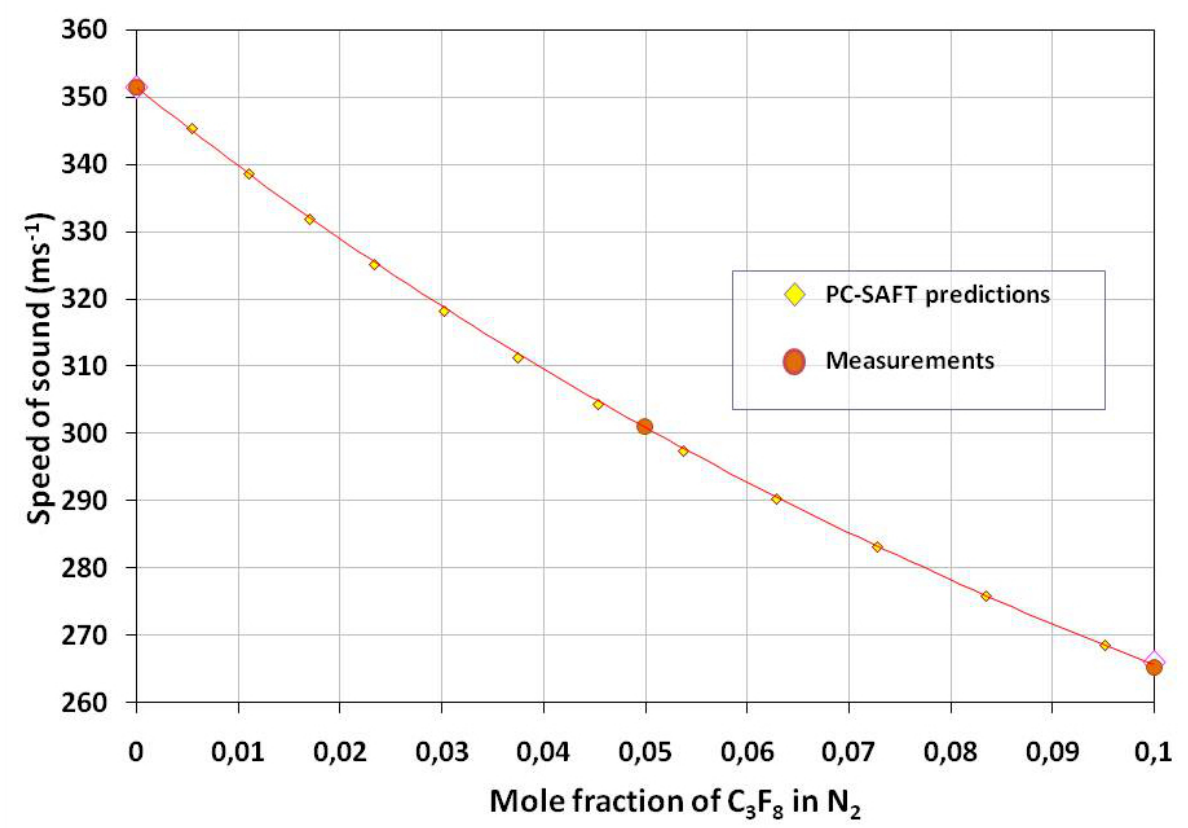

Figure 10. Comparison of sound velocity measurements ( $(\circ)$ and PC-SAFT predictions $(\diamond)$ in $\mathrm{C}_{3} \mathrm{~F}_{8} / \mathrm{N}_{2}$ mixtures at 1 bar abs and $25^{\circ} \mathrm{C}$. Mixture resolution is $\sim 4.10^{-5}$ for concentrations of $<1 \% \mathrm{C}_{3} \mathrm{~F}_{8}$ in $\mathrm{N}_{2}$.

$\mathrm{C}_{3} \mathrm{~F}_{8}$ to pure $\mathrm{N}_{2}$. The PC-SAFT equation of state was used as NIST-REFPROP is not presently configured for calculations of mixtures of saturated fluorocarbons with $\mathrm{N}_{2}$.

A reduction in sound velocity of $0.86 \mathrm{~ms}^{-1}$ from that of pure nitrogen is typically observed when the full pixel detector cooling system of 88 independent circuits is fully operating. From the $\sim 12.27 \mathrm{~ms}^{-1} \%^{-1}$ average gradient of the sound velocity-concentration curve for $\mathrm{C}_{3} \mathrm{~F}_{8}$ concentrations in the range $0 \rightarrow 0.5 \%$ (figure 10) this sound velocity difference indicates, via eq. (3.4), a $\mathrm{C}_{3} \mathrm{~F}_{8}$ leak ingress of $0.07 \%$ (figure 11). It is evident from comparison of figures 9 and 10 that the gradient of the sound velocity-composition curve (and consequently the resolution in mixture determination) improves considerably with increasing difference in molecular weights of the two components. Thus for $\mathrm{N}_{2} / \mathrm{C}_{3} \mathrm{~F}_{8}$ the intrinsic sound velocity uncertainty of around $\pm 0.05 \mathrm{~ms}^{-1}$ correspondingly yields a mixture uncertainty of $\pm 0.004 \%$.

Figure 11 illustrates a 1-year continuous $\log$ of the $\mathrm{C}_{3} \mathrm{~F}_{8}$ contamination of the pixel detector environmental $\mathrm{N}_{2}$ envelope. Fluctuations of the measured $\mathrm{C}_{3} \mathrm{~F}_{8}$ contamination are correlated with the development of leaks in some of the 88 individual cooling circuits, which have been identified by progressive turn-on or turn-off, but depend also on the purge rate of the $\mathrm{N}_{2}$ gas around the pixel detector, which is typically around $1 \mathrm{~m}^{3} \mathrm{hr}^{-1}$. Figure 12 illustrates the $\mathrm{C}_{3} \mathrm{~F}_{8}$ contamination increase seen in the progressive turn on of cooling circuit groups following the 2011-2012 newyear shutdown of the detector. Though none of the leaks is presently considered severe enough to require the related cooling circuit (and the corresponding section of the ATLAS pixel detector) to be shut down, figure 12 illustrates how the ultrasonic vapour analyzer can be used to rapidly identify a leaking circuit. 


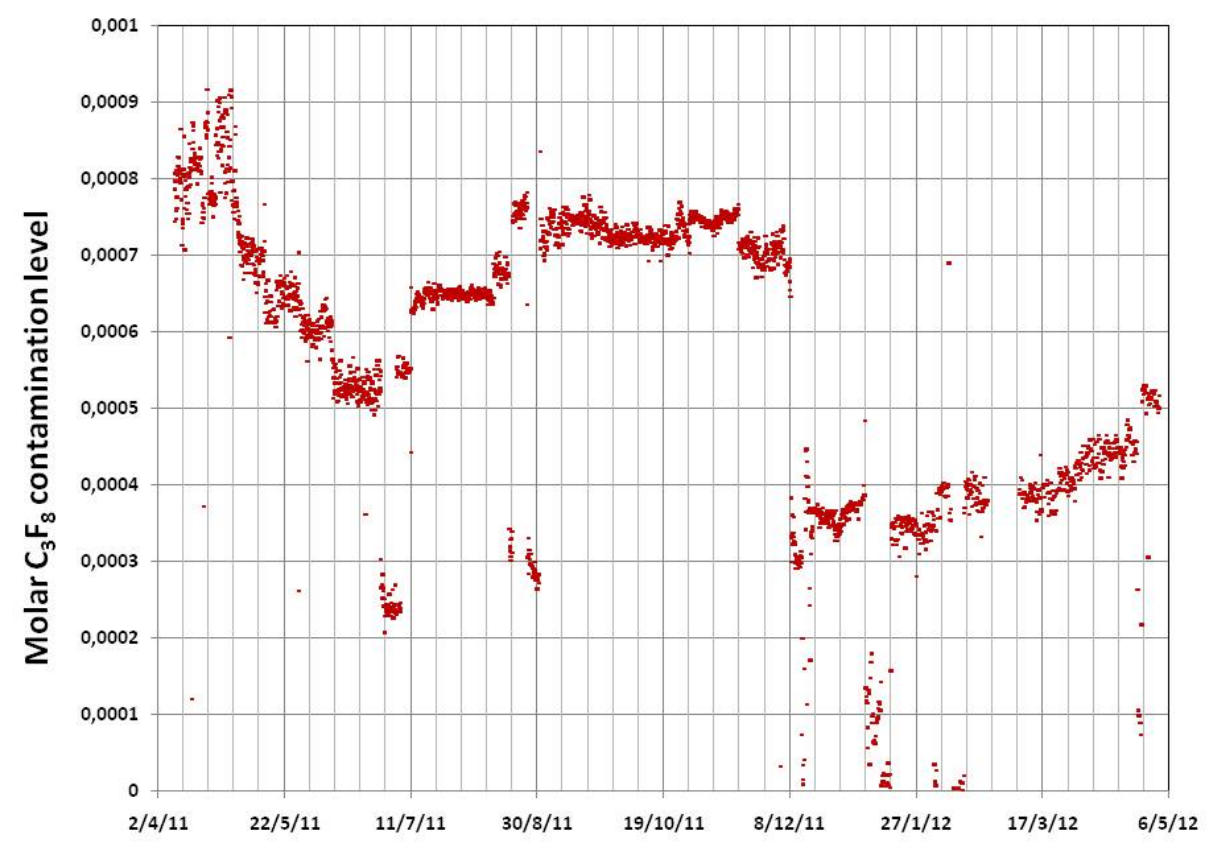

Figure 11. Long duration (1 year) $\log$ of $\mathrm{C}_{3} \mathrm{~F}_{8}$ leak contamination in the $\mathrm{N}_{2}$ environmental gas surrounding the ATLAS pixel detector.

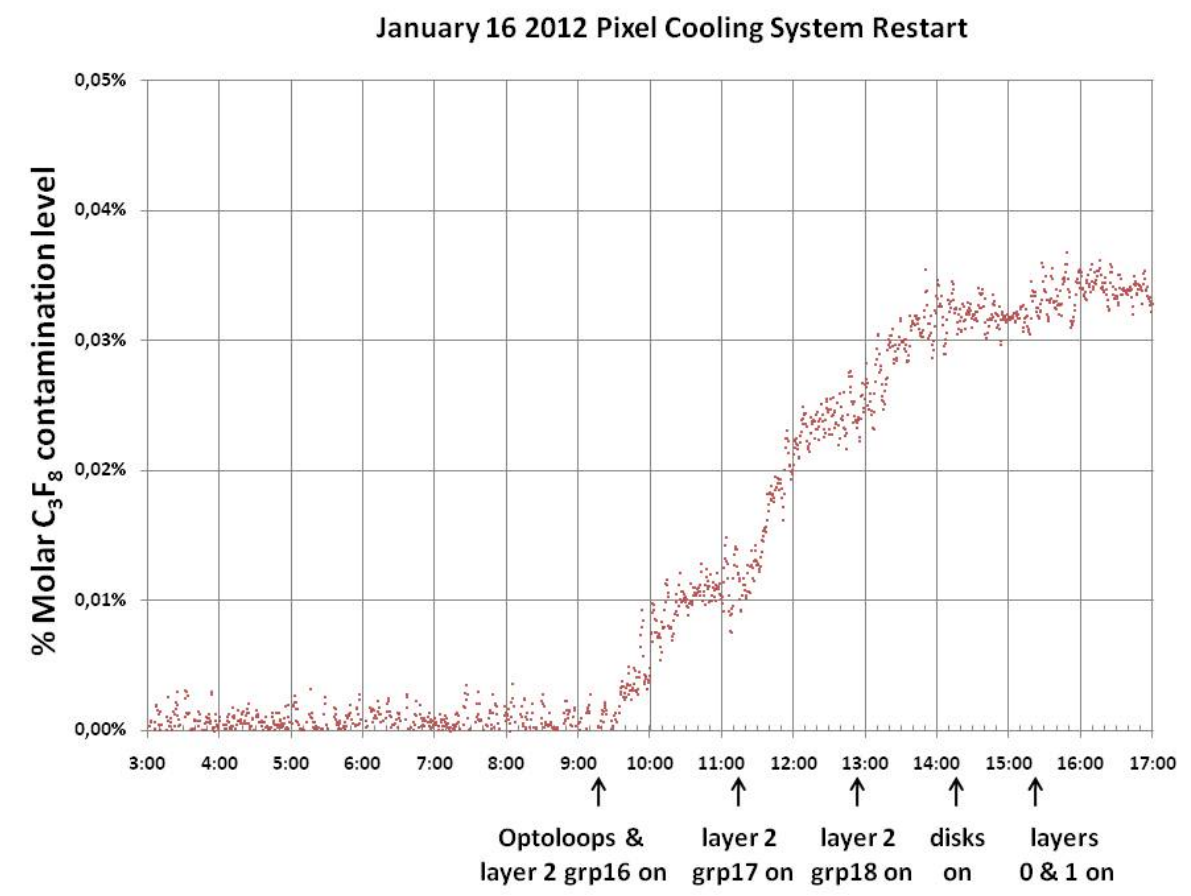

Figure 12. The increase of $\mathrm{C}_{3} \mathrm{~F}_{8}$ leak contamination during the progressive turn-on of cooling circuits of the ATLAS pixel detector, January 16, 2012. 


\subsection{Angled crossing geometry for analysis and flowmetry at flows up to $200001 . \mathrm{min}^{-1}$}

A high flow capacity ultrasonic flow meter/analyzer will be installed in the principal vapour return tube of the ATLAS $60 \mathrm{~kW}$ thermosiphon evaporative cooling recirculator [9] at a location where returning superheated fluorocarbon vapour will have a temperature of $20{ }^{\circ} \mathrm{C}$ and pressure of 500 mbar $_{\text {abs. }}$. An instrument with an "angled crossing" sound geometry has been developed for use in a flow of around $184001 . \mathrm{min}^{-1}$ in pure $\mathrm{C}_{3} \mathrm{~F}_{8}$ (around $200001 . \mathrm{min}^{-1}$ in a blend containing $70 \% \mathrm{C}_{3} \mathrm{~F}_{8} / 30 \% \mathrm{C}_{2} \mathrm{~F}_{6}$ ).

In its simplest implementation, an angled path ultrasonic flow meter consists of a pair of transducers of diameter $d$ separated by a distance $L$, and aligned on a sound path intersecting the main tube, of internal diameter $D_{\text {Main }}$, at an angle $\alpha$. The vapour flow rate is calculated from the opposed sound transit times, $\mathrm{t}_{\mathrm{down}}$, and $\mathrm{t}_{\mathrm{up}}$, according to the following algorithm:

$$
t_{\text {down }}=\frac{L}{(c+v \cos \alpha)}, \quad t_{\text {up }}=\frac{L}{(c-v \cos \alpha)}
$$

where $v$ is the linear flow velocity $\left(\mathrm{ms}^{-1}\right), c$ the speed of sound in the gas and the distance $L$ between transducers is entirely contained within the main flow tube of diameter, $D_{\text {Main }}$, implying $L \leq D_{\text {Main }} / \sin \alpha$.

The gas volume flow, $\mathrm{V},\left(\mathrm{m}^{3} \mathrm{~s}^{-1}\right)$ is inferred from the two transit times by:

$$
V=\frac{L \cdot \pi \cdot D_{\mathrm{Main}^{2}}\left(t_{\text {up }}-t_{\text {down }}\right)}{8 \cos \alpha\left(t_{\text {up }} \cdot t_{\text {down }}\right)}
$$

while the sound velocity can be inferred from the two transit times via:

$$
c=\frac{L\left(t_{\text {up }}+t_{\text {down }}\right)}{2\left(t_{\text {up }} \cdot t_{\text {down }}\right)}
$$

If the transducers are attached to the inner wall of the main tube they will impinge on the flow, creating eddies that will affect the measured gas flow velocity. A preferable geometry has the transducers backed-off an additional distance L' (counting both sides) to position their inner edges flush with the internal surface of the main tube. This minimal non-impinging transducer spacing can be defined as:

$$
L=\frac{D_{\text {Main }}}{\sin \alpha}+L^{\prime}, \quad \text { where } \quad L^{\prime}=\frac{d}{\tan \alpha}
$$

Alternatively the transducers may be withdrawn a longer distance $L^{\prime}$ with respect to the internal surface of the main tube. The latter configuration with a pair of transverse tube stubs allows the changing of a transducer without interruption of the main gas flow: the transducers can be backed off outboard of quarter-turn ball valves, which when open allow the sound path to traverse the main tube.

In configurations where the transducer spacing includes an element $L^{\prime}$ containing quasi-static vapour in communication with the flow in the main tube the formalism for calculating the flow velocity is modified from that of eq. (3.5) as follows:

$$
t_{\text {down }}=\frac{L^{\prime}}{c}+\frac{D_{\text {Main }}}{\sin \alpha(c+v \cos \alpha)}, \quad t_{\text {up }}=\frac{L^{\prime}}{c}+\frac{D_{\text {Main }}}{\sin \alpha(c-v \cos \alpha)}
$$


The sound velocity, $c$, is the physical root derived from the relations of eq. (3.9) in terms of measurables $L, D_{\text {Main }}, \alpha, t_{\text {up }}$ and $t_{\text {down }}$ :

$$
c=\frac{\left(t_{\text {up }}+t_{\text {down }}\right)\left(2 L^{\prime}+\frac{D_{\text {Main }}}{\sin \alpha}\right) \pm \sqrt{\left(t_{\text {up }}+t_{\text {down }}\right)^{2}\left(2 L^{\prime}+\frac{D_{\text {Main }}}{\sin \alpha}\right)^{2}-\left(16 L^{\prime} t_{\text {up }} t_{\text {down }}\left(L^{\prime}+\frac{D_{\text {Main }}}{\sin \alpha}\right)\right)}}{4 t_{\text {up }} t_{\text {down }}}
$$

allowing the gas flow velocity, v, to be calculated as

$$
v=\frac{c\left(c t_{\mathrm{up}}-\frac{D_{\mathrm{Main}}}{\sin \alpha}-L^{\prime}\right)}{\cos \alpha\left(c t_{\mathrm{up}}-L^{\prime}\right)}
$$

or as

$$
v=\frac{c\left(\frac{D_{\text {Main }}}{\sin \alpha}+L^{\prime}-c t_{\text {down }}\right)}{\cos \alpha\left(c t_{\text {down }}-L^{\prime}\right)}
$$

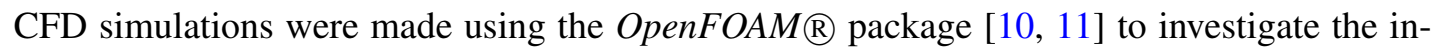
teraction between the vapour flow in the main tube and the placement of the ultrasonic transducers. The interaction of the flow with the static vapour in the two tube stubs of total length L' was also of interest since the transmitted sound pulse might be expected to be disturbed by the presence of vortices in the tube stubs.

Each of the following transducer spacing configurations illustrated in figure 13a-c was evaluated:

a. $L=3 D_{\text {Main }} / \sin \alpha$ : transducers far from the main tube to minimize turbulence effects and allow for valve isolation - figure 13a;

b. $L=D_{\text {Main }} / \sin \alpha+d / \tan \alpha$ : transducer edges flush with the inner wall of the main tube figure $13 b$;

c. $L=D_{\text {Main }} / \sin \alpha$ : half of each transducer face (diameter, $d,=44 \mathrm{~mm}$ ) impinging on the flow in the main tube - figure 13c.

In all cases, the flow conditions were chosen to correspond to those in the main vapour return of the future thermosiphon recirculator, with a mass flow of $1.2 \mathrm{kgs}^{-1}$ of $\mathrm{C}_{3} \mathrm{~F}_{8}$ at $20^{\circ} \mathrm{C}$ and a pressure of 500 mbar $_{\text {abs }}$, (density $3.901 \mathrm{kgm}^{-3}$ ).

In each transducer configuration simulations were made with sound tube crossing angles of $15^{\circ}, 30^{\circ}$ and $45^{\circ}$. In each case two alternatives $(133.7$ and $211.6 \mathrm{~mm})$ were considered for the main tube internal diameter (corresponding to the two most probable choices, using standard tube sizes), with corresponding $\mathrm{C}_{3} \mathrm{~F}_{8}$ average linear flow velocities of 21.92 and $8.75 \mathrm{~ms}^{-1}$. In addition three simulations were made, corresponding to the three crossing angles for half flow in a main tube of internal diameter $133.7 \mathrm{~mm}$.

The number of cells used in the simulation mesh varied between 3 and 8 million, depending on the geometry. The SST $k-\omega$ [11] turbulence model was adopted in the CFD simulations. Since the fluid flow velocity is lower than Mach 0.3 the resulting variation of density within the system is negligible, allowing the flow in the tube to be modelled as incompressible.

Figure 14 shows negligible influence of the sound tube stubs on the main stream for the case of maximum $\left(3 D_{\text {Main }} / \sin \alpha\right)$ transducer spacing, corresponding to figure 13a. The stream lines 


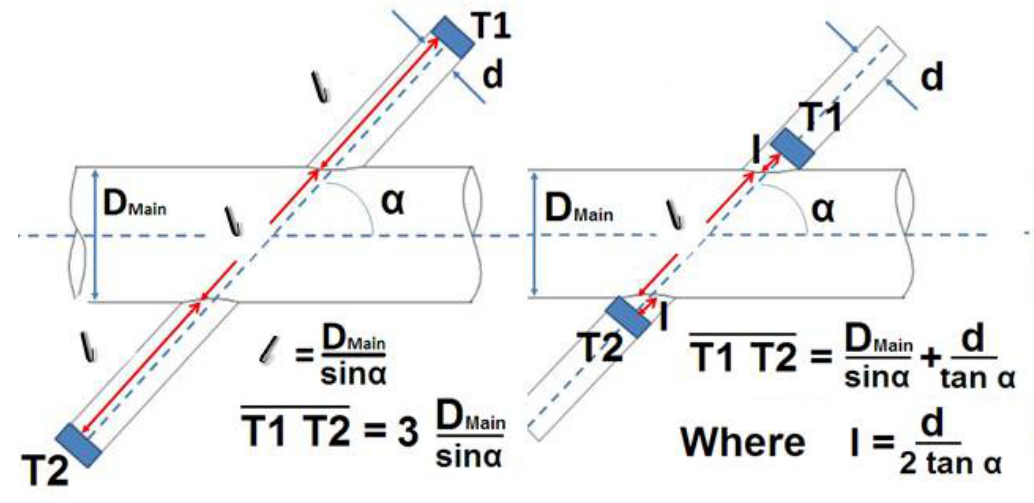

(a) (b)

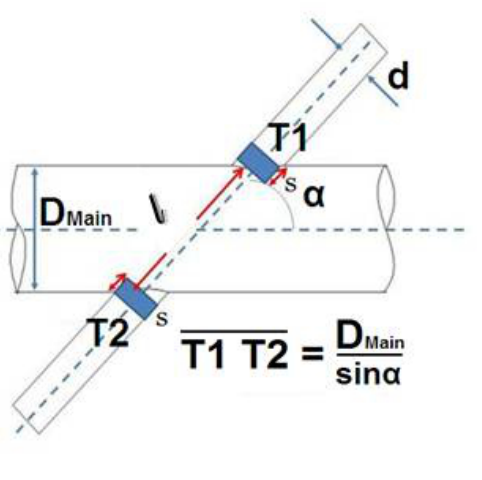

(c)

Figure 13. Angled flow meter configuration with: (a) 'maximum' transducer spacing $\left(3 D_{\text {Main }} / \sin \alpha\right)$;

(b) 'mid' transducer spacing $\left(D_{\text {Main }} / \sin \alpha+d / \tan \alpha\right)$;

(c) 'minimum' transducer spacing $\left(D_{\text {Main }} / \sin \alpha\right)$, with transducers impinging on the main flow.

remain parallel to each other even close to the stub intersections. Due to the drag force of the main stream on the quasi-static vapour in the sound tube stubs, a slow counterclockwise-rotating vortex occurs in the upper (downstream) stub, while a clockwise-rotating vortex occurs in the lower (upstream) stub. Despite these vortices, the average vapour speed in the two sound tube stubs must be zero, from conservation of mass. It can be seen that a wake follows the downstream tube stub, although this does not influence the flow measurement as it lies outside the sound path. The result is a rather uniform axial velocity distribution across the diameter of the main tube, as shown in figure 15 .

The area of the elliptical aperture, $a$, formed by the intersection of the inner diameter, $D_{s}$, of transversal sound tube stubs and the main tube is given by:

$$
a=\frac{D_{s}^{2}}{4 \sin \alpha} .
$$

The effect of elliptical aperture variation can be seen in figure 15. At the shallower crossing angles of $15^{\circ}$ and $30^{\circ}$ the larger aperture is manifested as a slight increase in the effective diameter of the main tube at the aperture of the downstream sound tube stub. At $45^{\circ}$ crossing angle, however, the effective diameter corresponds closely to that of the main tube. Simulations were not therefore carried out at crossing angles exceeding $45^{\circ}$ since the $\left(t_{\text {up }}-t_{\text {down }}\right)$ transit time difference is progressively reduced as $\alpha$ tends toward $90^{\circ}$, resulting in reduced accuracy in flow measurement. Following the conclusion of prototype tests, discussed later, a crossing angle of $45^{\circ}$ was adopted for the final instrument, this also being mechanically easier to fabricate in a dissimilar diameter tube cross than the more oblique angles.

The flow profiles in the main tube for the transducer configurations of figures $13 \mathrm{a}$ and $13 \mathrm{~b}$ are similar, (as shown in figures 14 and 16) and exhibit no major influence of the transducers over the main stream flow. On the other hand, in the configuration of figure $13 \mathrm{c}$ half the surface area of each transducer is immersed in the main stream. These obstructions create vortices in the sound path near the transducers (figure 17), reducing the accuracy of sound transit time difference 


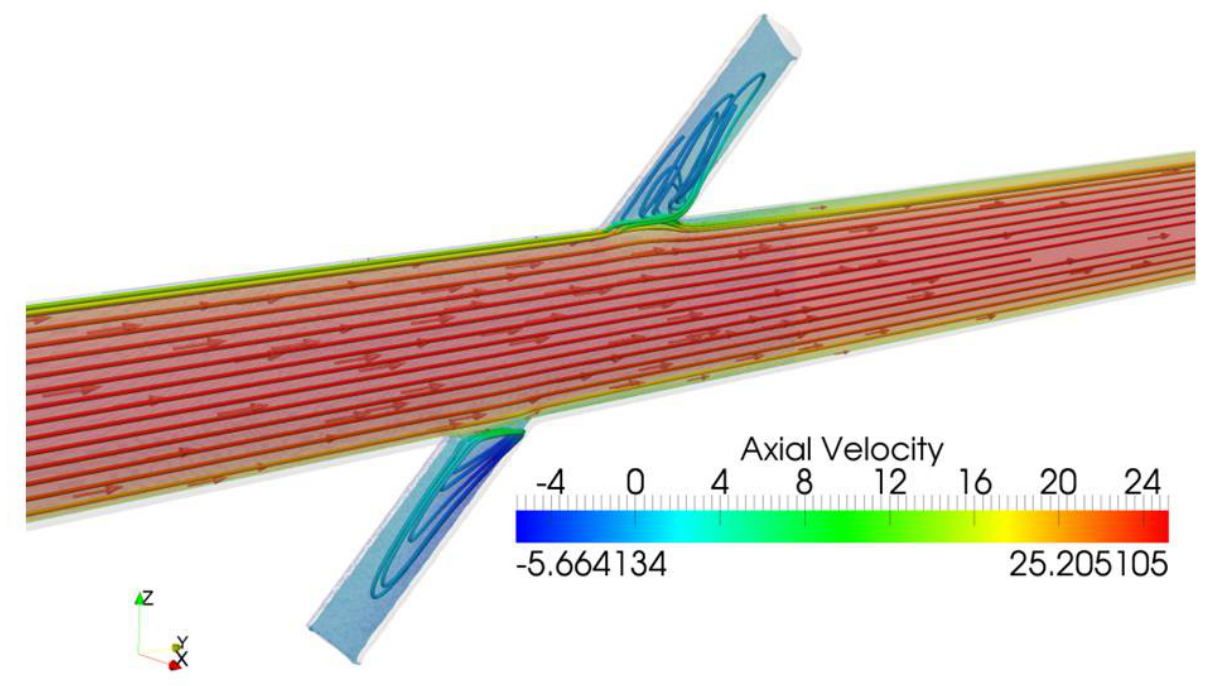

Figure 14. Contours of the axial component of gas flow velocity $\left(\mathrm{ms}^{-1}\right)$ on the symmetry plane with stream lines: transducer spacing $\left(3 D_{\text {Main }} / \sin \alpha\right), 45^{\circ}$ intersection and $D_{\text {Main }}=133.7 \mathrm{~mm}$.

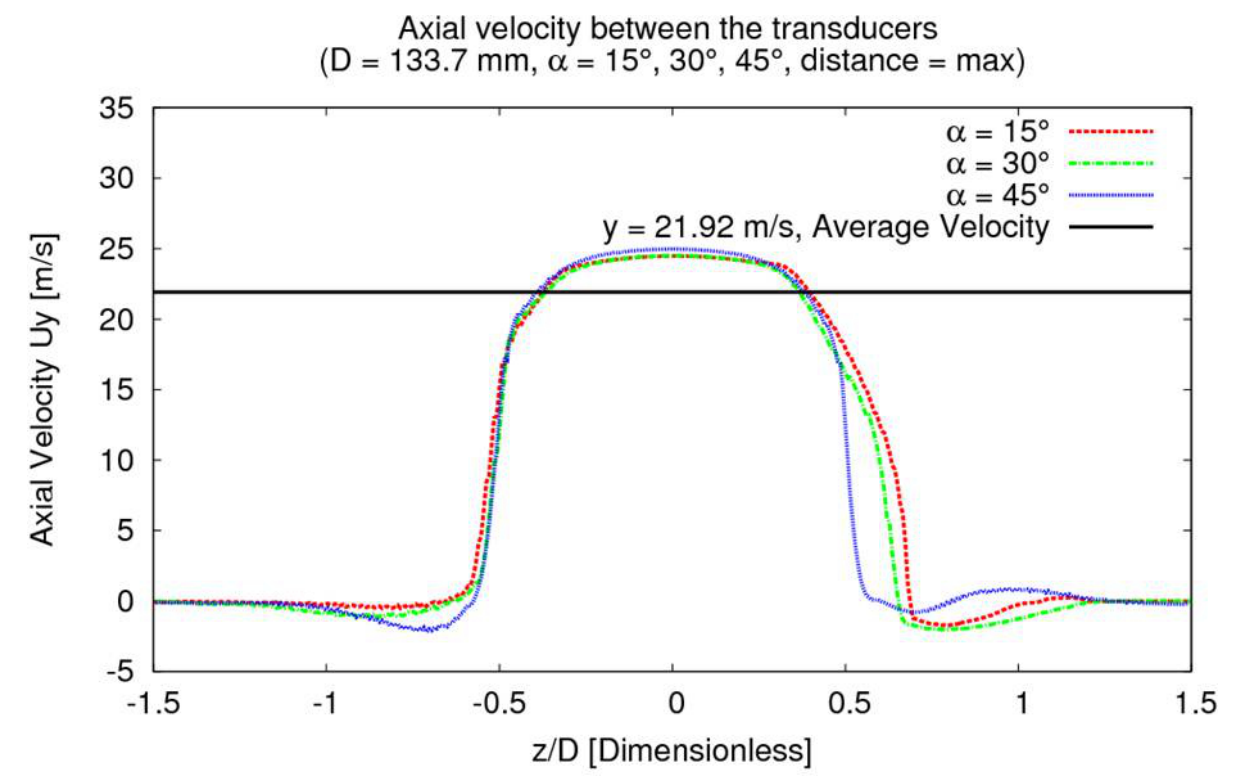

Figure 15. Axial flow velocity in (and beyond) the main tube vs. position along the sound path between the transducers in the configuration with $\left(3 D_{\text {Main }} / \sin \alpha\right)$ spacing. The position along the sound path is a dimensionless projection perpendicular to the axis of the main tube and normalised to $D_{\text {Main }}$. The average velocity in the $133.7 \mathrm{~mm}$ diameter main tube is $21.92 \mathrm{~ms}^{-1}$. 


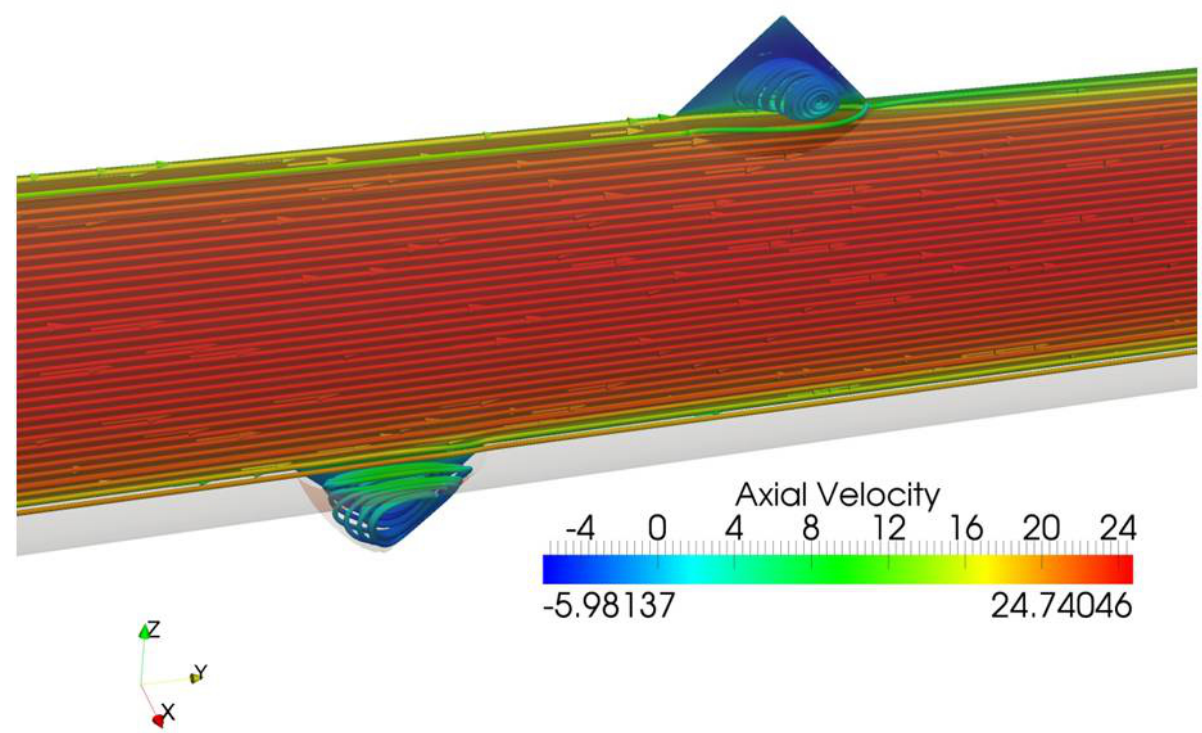

Figure 16. Contours of the axial component of velocity on the symmetry plane $\left(\mathrm{ms}^{-1}\right)$, with stream lines: transducer spacing $\left(D_{\text {Main }} / \sin \alpha .+d / \tan \alpha\right), 45^{\circ}$ crossing and $D_{\text {Main }}=133.7 \mathrm{~mm}$.

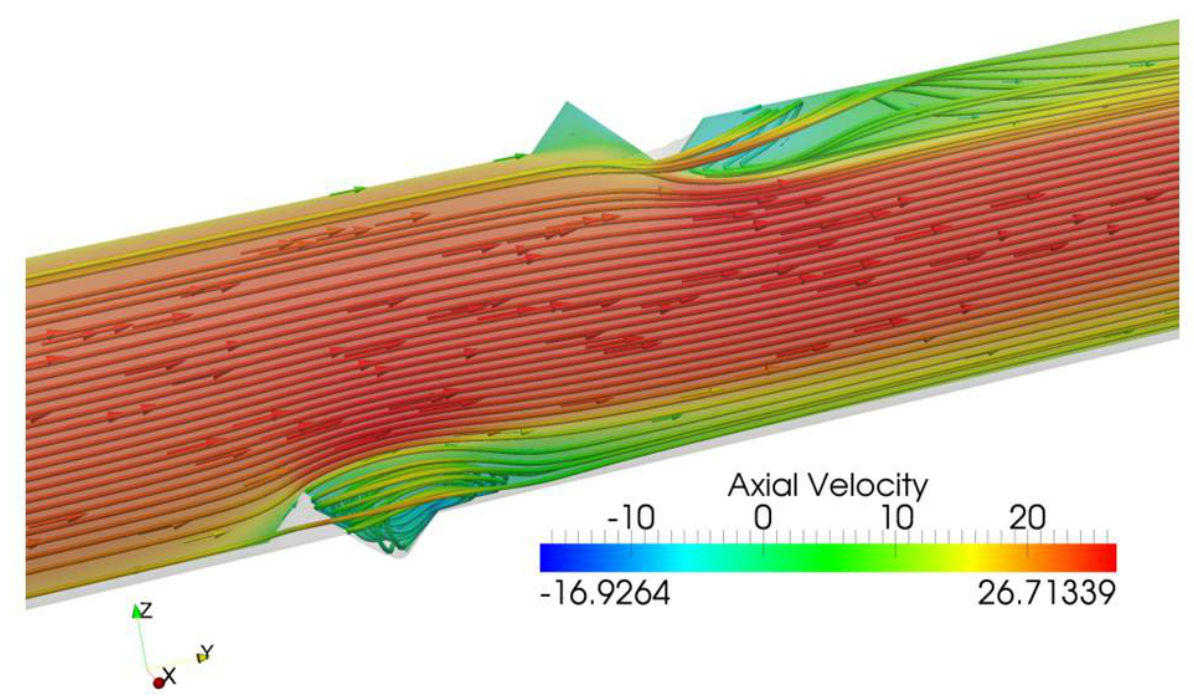

Figure 17. Contours of the axial component of velocity on the symmetry plane $\left(\mathrm{ms}^{-1}\right)$ with stream lines: transducer spacing $\left(D_{\text {Main }} / \sin \alpha\right)$ with $45^{\circ}$ crossing and $D_{\text {Main }}=133.7 \mathrm{~mm}$. Roughly half the surface area of each transducer impinges into the flowing vapour.

measurements. For this reason we have not pursued an internally-mounted transducer configuration through to prototyping.

Table 3 compares the CFD-reconstructed average axial flow velocity, $V_{c}$, (column 3 ) with the "start condition" average flow, $v$, in the main tube (column 2) for the 21 different geometrical and flow combinations that were simulated. Geometric corrections for the different fractional lengths of the sound path in the flowing gas are also evaluated. The results for the two different main tube diameters, $D_{\text {Main }}$, show no major influence of this parameter on the calculated flow except in the 
Table 3. Comparison of CFD-calculated average axial flow velocities, $V_{c}$, in the inter-transducer sound volume with "starting value" average axial flow, $v$, in the main tube. Geometric deficits, $G D$, and expected geometric (sound path) correction factors, $G C F$, to $V_{c}$ are shown. Calculations made at half nominal flow are shown in italics.

\begin{tabular}{|c|c|c|c|c|c|c|c|}
\hline $\begin{array}{c}\text { Transducer } \\
\text { configuration } \\
\text { (figure 13): } \\
D_{\text {Main }}(\mathrm{mm}) \text {, } \\
\alpha\left(^{\circ}\right)\end{array}$ & $\begin{array}{c}v \\
\left(\mathrm{~ms}^{-1}\right)\end{array}$ & $\begin{array}{c}V_{c} \\
\left(\mathrm{~ms}^{-1}\right)\end{array}$ & $\begin{array}{l}\text { CFD calculated } \\
\text { axial flow } \\
\text { velocity deficit } \\
\text { (\%) }\end{array}$ & $\begin{array}{l}G D \\
(\%)\end{array}$ & $\begin{array}{c}\text { (CFD }-G D) \\
\text { difference }(\%) \\
\text { (with } \pm 1.5 \% \\
\text { uncertainty) }\end{array}$ & $G C F$ & $\begin{array}{c}\text { Interface } \\
\text { aperture }\left(\mathrm{cm}^{2}\right) \\
(5 \mathrm{~cm} \text { ID } \\
\text { sound tube })\end{array}$ \\
\hline $133.7,15^{\circ}$, (a) & 21.92 & 7.81 & 64.4 & 66.6 & $(2.2 \pm 1.5) \%$ & 3 & 75.9 \\
\hline $133.7,30^{\circ}$, (a) & 21.92 & 7.50 & 65.8 & 66.6 & 0.8 & 3 & 39.3 \\
\hline $133.7,45^{\circ}$, (a) & 21.92 & 8.05 & 63.3 & 66.6 & 3.3 & 3 & 27.8 \\
\hline $133.7,15^{\circ},(b)$ & 21.92 & 17.71 & 19.2 & 24.1 & 4.9 & 1.32 & 75.9 \\
\hline $133.7,30^{\circ},(b)$ & 21.92 & 17.68 & 19.3 & 22.2 & 2.9 & 1.29 & 39.3 \\
\hline $133.7,45^{\circ},(b)$ & 21.92 & 17.43 & 20.5 & 18.9 & 1.65 & 1.23 & 27.8 \\
\hline $133.7,15^{\circ},(\mathrm{c})$ & 21.92 & 19.29 & 12.0 & 0 & 12 & 1 & 75.9 \\
\hline $133.7,30^{\circ},(\mathrm{c})$ & 21.92 & 18.17 & 17.1 & 0 & 17.1 & 1 & 39.3 \\
\hline $133.7,45^{\circ},(\mathrm{c})$ & 21.92 & 19.00 & 13.3 & 0 & 13.3 & 1 & 27.8 \\
\hline $133.7,30^{\circ},(a)$ & 10.96 & 3.76 & 65.7 & 66.6 & 0.9 & 3 & 39.3 \\
\hline $133.7,30^{\circ},(\mathrm{b})$ & 10.96 & 8.80 & 19.7 & 24.1 & 4.4 & 1.29 & 39.3 \\
\hline $133.7,30^{\circ},(\mathrm{c})$ & 10.96 & 9.20 & 16.0 & 0 & 16 & 1 & 39.3 \\
\hline $211.6,15^{\circ}$, (a) & 8.75 & 2.95 & 66.3 & 66.6 & 0.3 & 3 & 75.9 \\
\hline $211.6,30^{\circ},(\mathrm{a})$ & 8.75 & 2.84 & 67.5 & 66.6 & -0.9 & 3 & 39.3 \\
\hline $211.6,45^{\circ}$, (a) & 8.75 & 2.85 & 67.4 & 66.6 & -0.8 & 3 & 27.8 \\
\hline $211.6,15^{\circ},(b)$ & 8.75 & 7.72 & 11.8 & 16.7 & 4.9 & 1.20 & 75.9 \\
\hline $211.6,30^{\circ},(\mathrm{b})$ & 8.75 & 7.64 & 12.7 & 15.3 & 2.6 & 1.18 & 39.3 \\
\hline $211.6,45^{\circ},(b)$ & 8.75 & 7.71 & 11.8 & 12.8 & 1 & 1.15 & 27.8 \\
\hline $211.6,15^{\circ},(\mathrm{c})$ & 8.75 & 8.20 & 6.3 & 0 & 6.3 & 1 & 75.9 \\
\hline $211.6,30^{\circ},(\mathrm{c})$ & 8.75 & 8.03 & 8.3 & 0 & 8.3 & 1 & 39.3 \\
\hline $211.6,45^{\circ},(\mathrm{c})$ & 8.75 & 8.16 & 6.8 & 0 & 6.8 & 1 & 27.8 \\
\hline
\end{tabular}

case (figure 13c) where the transducers impinge on the flow in the main tube. While the choice with $D_{\text {Main }}=211.6 \mathrm{~mm}$ would allow for a lower pressure drop, the choice with $D_{\text {Main }}=133.7 \mathrm{~mm}$ is preferable for measurement accuracy, since the velocity component parallel to the sound wave is greater. An inner diameter of $133.7 \mathrm{~mm}$ has been subsequently chosen for the local tubing where the ultrasonic flowmeter/analyzer will be installed.

The CFD-calculated average velocity component, $V_{c}$, in the direction of flow in the main tube (table 3 column 3 ) is averaged in a cylindrical volume defined by the diameter and spacing of the two transducers, using axial velocity values at points along the whole sound path, including where applicable - the regions beyond the confines of the main flow tube. The signed percentage deficit of the calculated flow, $V_{c}$, from the average "starting value" axial flow, $v$, in the main tube, 
is given by $\left(\left(v-V_{c}\right) / v\right)$, and is shown in column 4 of table 3 , where it is also compared with the simple expected geometrical deficit, $G D$. $G D$ can be expressed as a percentage based on the ratio of the sound path crossing the flowing vapour, $\left(D_{\text {Main }} / \sin \alpha\right)$, to the total length, $L$, including the path length, $L^{\prime}$, in quasi-static vapour:

$$
G D=\frac{100\left(L-\frac{D_{\text {Main }}}{\sin \alpha}\right)}{L}
$$

Taking an example for the configuration of figure $13 \mathrm{a}$ with $15^{\circ}$ crossing angle in a $137.1 \mathrm{~mm}$ diameter main tube, a value of $64.4 \%$ for $\left(\left(v-V_{c}\right) / v\right)$ is calculated from CFD. In this geometry $2 / 3$ of the sound path is characterized by quasi-static flow. The expected geometric deficit from sound path arguments according to eq. (3.13) would be $66.6 \%$, meaning that the flow velocity measured in such an instrument would need to be multiplied by a geometrical correction factor, $G C F$, to find the axial flow velocity in the main tube, where (maintaining the sign convention of the expected geometric deficit) $G C F$ is expressed in terms of $G D$ as:

$$
G C F=\left(1-\frac{G D}{100}\right)^{-1}
$$

In the configuration of figure $13 \mathrm{a}, G C F=3$, while in the configuration of figure $13 \mathrm{~b} G C F$ depends explicitly on the crossing angle and main tube diameter, as shown in column 7 of table 3 . In the configuration of figure $13 \mathrm{c}$, where the entire sound path is in the flowing vapour, $G C F$ would be unity.

The difference between the CFD-calculated average axial velocity deficit (table 3 column 4) and the expected geometrical deficit (table 3 column 5) is a quality estimator for the particular geometry of ultrasonic flow meter, taking into account the effects of turbulence and vortices in the sound path which are only accessible via the CFD analysis. It can be seen from table 3 that the differences are minimised in the geometry of figure 13a where the transducers are backed off a significant distance from the main tube. In this geometry the average CFD computed deficit was $(65.77 \pm 1.52) \%$. The standard deviation of the deficits calculated from the 7 independent CFD analyses is thus a reasonable indicator of the precision of CFD predictions and can be applied to data in column 6 of table 3 .

It can also be seen (table 3 column 8 ) that the elliptical interface area of the intersecting sound tubes (or the transducer and its support in the geometry of figure 14c) has little influence on the CFD reconstructed average axial velocity for crossing angles between 15 and $45^{\circ}$.

While most of the data in table 3 were calculated at the nominal fluorocarbon mass flow rate of $1.2 \mathrm{kgs}^{-1}$ expected in thermosiphon operation at the full cooling capacity of $60 \mathrm{~kW}$, simulations were also carried out at half-flow in a tube of $133.7 \mathrm{~mm}$ internal diameter and a sound path angle of $30^{\circ}$ for each of the three transducer configurations if figure 13 . These studies were aimed to check for possible variations of the velocity distribution with the flow rate in the main tube, which might make it difficult to calibrate the instrument. These results are shown in italics in table 3 while the axial flow velocity profile across the main tube is compared with that at full flow in figure 18 . The similarity of the flow profiles and the expected deficits - calculated according to eqs. (3.13) and (3.14) - for $30^{\circ}$ crossing angle at full and half flow leads us to believe that the variations in turbulence within the sound path are insignificant over the flow range expected, and that the calibration of the instrument against, for example, a volumetric flow meter should be linear. 

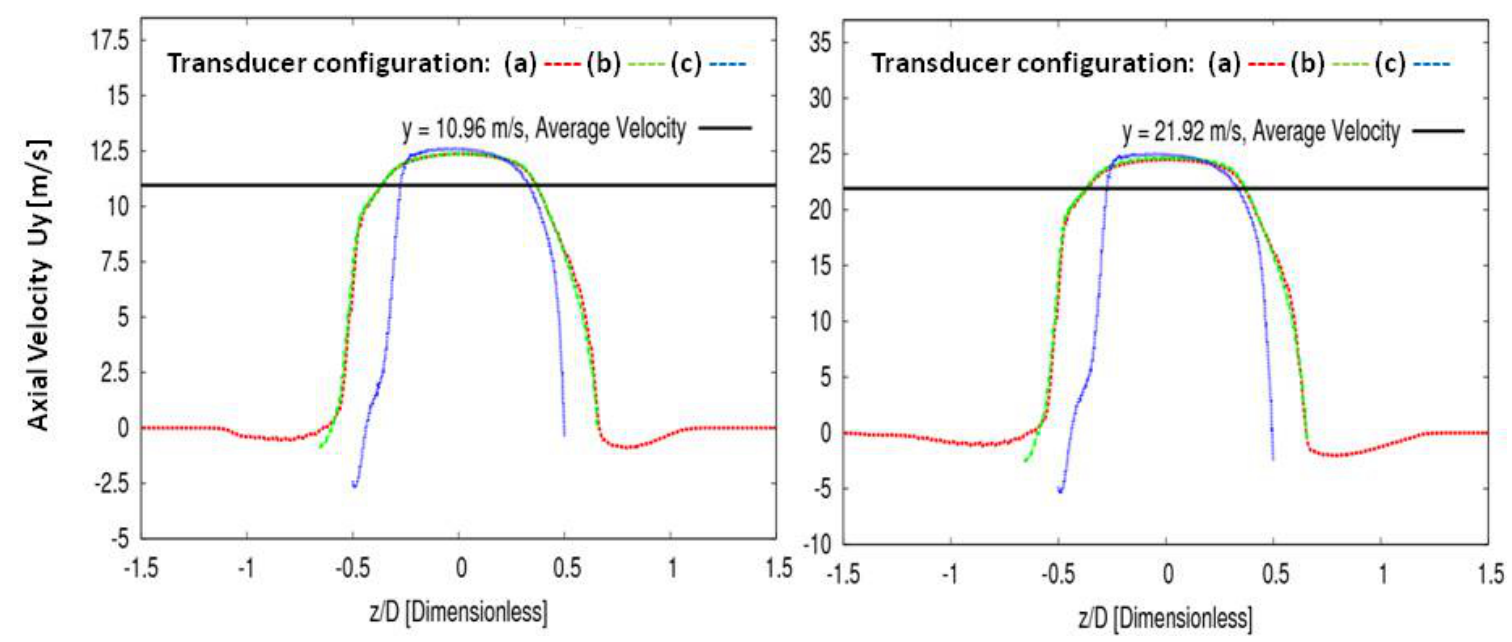

Figure 18. Axial flow velocity in (and beyond) the $133.7 \mathrm{~mm}$ diameter main tube vs. position along the sound path between the transducers in the three configurations for $30^{\circ}$ crossing angle: right: at full flow of $21.92 \mathrm{~ms}^{-1}$; left: at half flow of $10.96 \mathrm{~ms}^{-1}$. The position along the sound path is a dimensionless projection perpendicular to the axis of the main tube and normalised to $D_{\text {Main }}$.

In conclusion, CFD simulations have shown that the angled flow meter with transducers withdrawn from the main flow stream can provide a reliable measurement of the average flow velocity, since:

- the sound path covers the whole velocity profile of the main stream;

- the device does not significantly influence the flow;

- vapour in the intersecting sound tube stubs is almost static and the vortices in them are slow;

- calibration is straightforward as the velocity distribution is uniform also for different flow rates;

- the slight turbulent effects do not appear to degrade the sound path over the expected flow range;

- a crossing angle of $45^{\circ}$ is preferred.

We have constructed and tested a prototype ultrasonic flowmeter (figures 19,20) with $45^{\circ}$ crossing angle using PVC tubing of similar diameter to that foreseen in the ATLAS thermosiphon installation. The flowmeter was based on a sound tube of $45 \mathrm{~mm}$ inner diameter crossing a main tube of $103 \mathrm{~mm}$ inner diameter, integrated into an air 'cannon' of total length $7 \mathrm{~m}$. The total sound path length was $695 \mathrm{~mm}$, with $550 \mathrm{~mm}$ being in static gas in the tube stubs.

The extra length of the sound tube stubs included the lengths of quarter turn ball valves to allow testing of a geometry similar to the final instrument, allowing transducer changeover without stopping the flowing fluorocarbon vapour. 


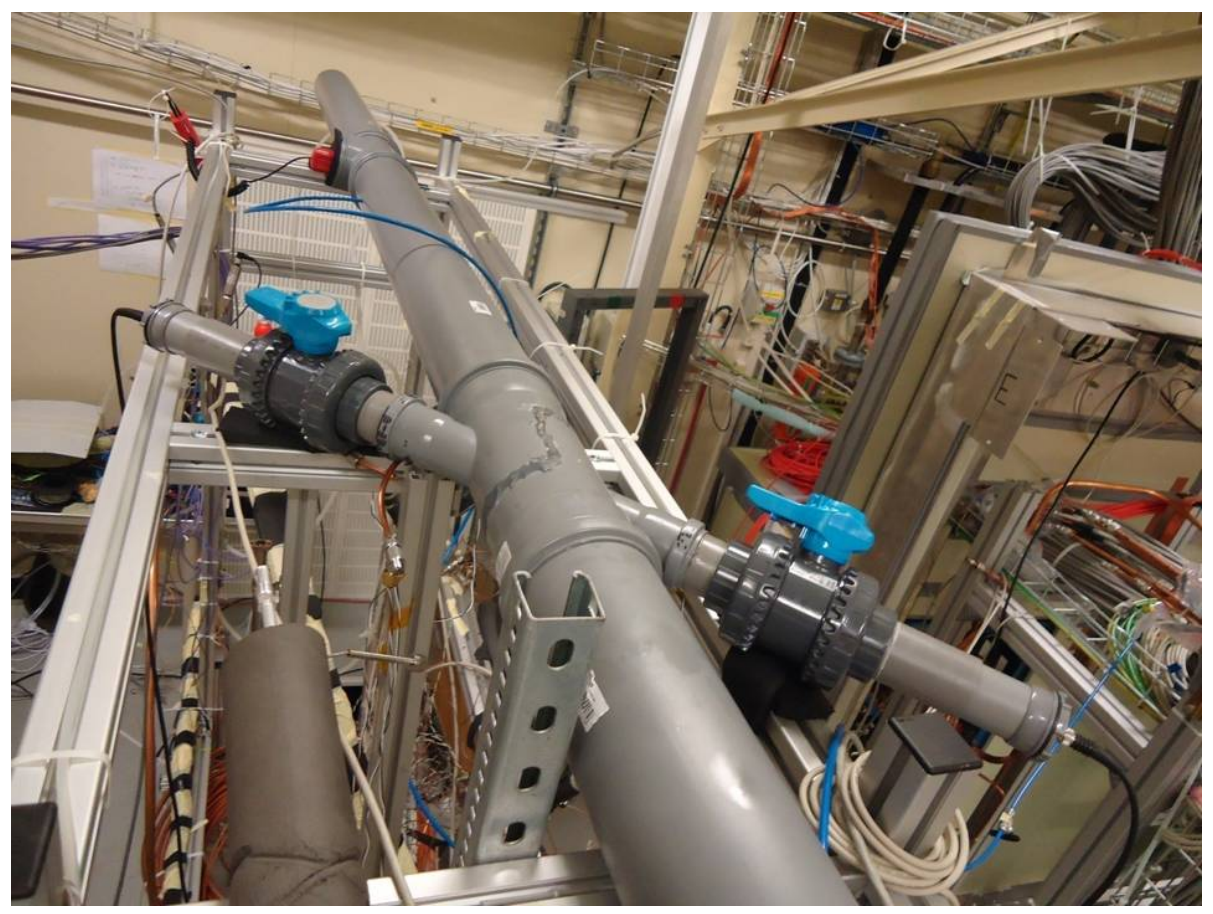

Figure 19. Prototype angled ultrasonic flowmeter with $45^{\circ}$ crossing angle implemented in PVC tubing of $103 \mathrm{~mm}$ internal diameter.

Air was injected from a standard 8 bar building delivery network via a venturi, which could aspirate additional room air for a total maximum flow velocity of around $16 \mathrm{~ms}^{-1}$. The ultrasonic flowmeter was calibrated against an anemometer ${ }^{4}$ installed downstream, as shown in figure 19. The gas flow velocity in the ultrasonic flowmeter was calculated according to the formalism of eqs. (3.10) and (3.11a), (3.11b). The horizontal error bars in the upper plot of figure 20 (and the vertical error bars in the lower plot of figure 20) represent the quoted $2 \%$ of full scale error of the anemometer. In the upper plot of figure 20 the vertical error bars of $\pm 3.1 \%$ of reading reflect the combination of the uncertainty in sound velocity measurement $\left( \pm 0.05 \mathrm{~ms}^{-1}\right)$, crossing angle in the PVC tube $\left( \pm 1^{\circ}\right)$, PVC main tube diameter $( \pm 1 \mathrm{~mm})$, timing precision $( \pm 100 \mathrm{~ns})$ and transducer spacing ( $\pm 0.1 \mathrm{~mm}$ following length calibration in a quasi-ideal static gas, according to the procedure discussed in section 5). The main tube diameter and sound tube crossing angle uncertainty represent the dominant error contributions to the measured flow rate: respectively $\pm 1.8 \%$ and $\pm 2.2 \%$. The rms accuracy of the ultrasonic flowmeter relative to the fit is equivalent to $\pm 1.9 \%$ of the full scale flow of $15 \mathrm{~ms}^{-1}$ achievable with the available compressed air supply.

Although calibration with expensive fluorocarbons and their mixtures was not possible in an open system, the encouraging test results have permitted the construction to start on a full scale stainless steel angled ultrasonic flowmeter with $45^{\circ}$ crossing angle and a main tube of $137 \mathrm{~mm}$ inner diameter.

\footnotetext{
${ }^{4}$ Amprobe model TMA10A: $25 \mathrm{~ms}^{-1}$ full scale, intrinsic accuracy $\pm 2 \% \mathrm{FS}$.
} 


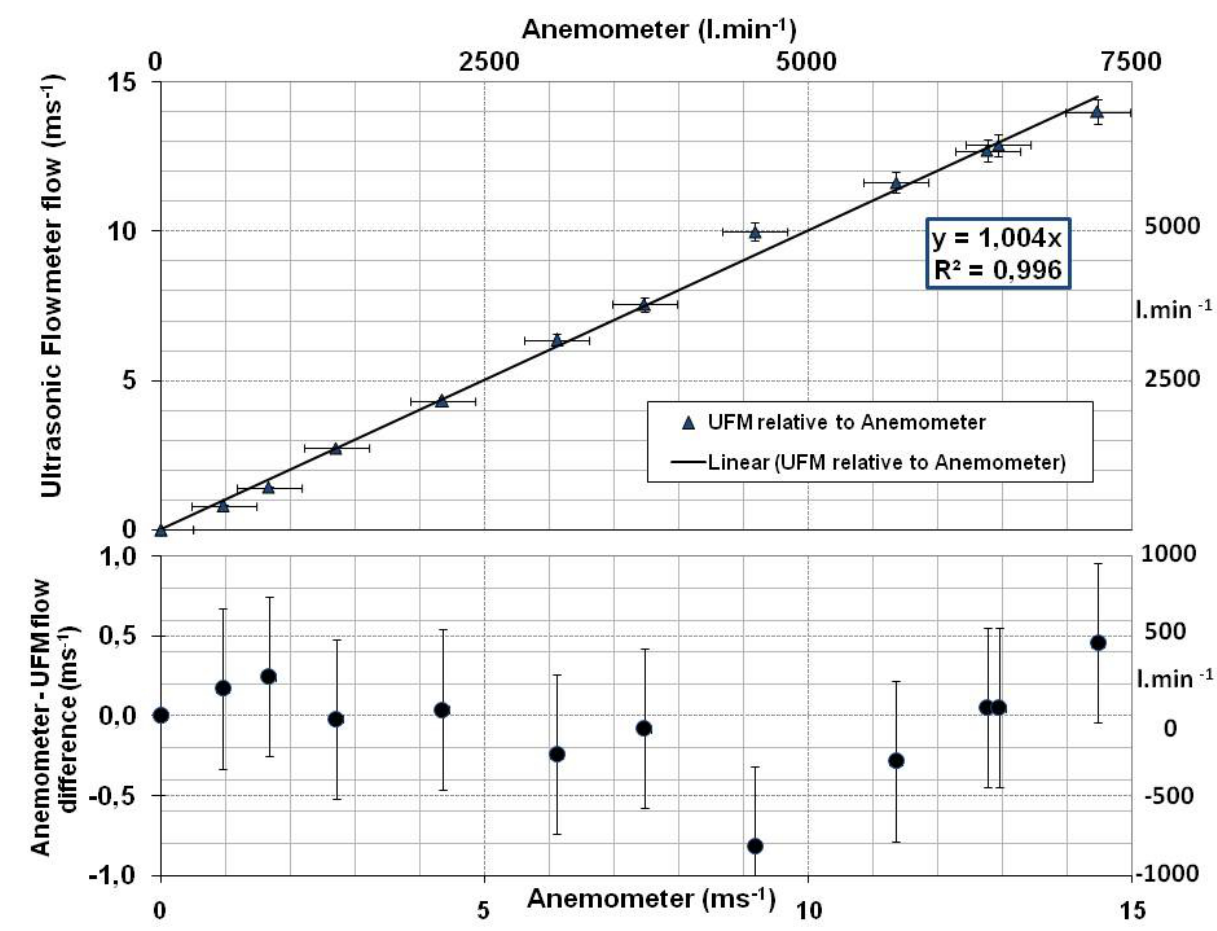

Figure 20. Upper plot: calibration of the PVC prototype $45^{\circ}$ angled ultrasonic flowmeter vs. Amprobe TMA10A anemometer. Lower plot: differences between the anemometer and ultrasonic flowmeter plotted with error bars representing the quoted anemometer uncertainty of $\pm 2 \%$ of the full scale of $25 \mathrm{~ms}^{-1}$.

\section{Electronics}

The custom electronics — shown in figure 21 - is based on a Microchip ${ }^{\circledR}$ dsPIC 16 bit microcontroller. This generates the $50 \mathrm{kHz}$ sound burst signals emitted by the transducers and includes a $40 \mathrm{MHz}$ transit clock that is stopped when an amplified sound signal from a receiving transducer crosses a user-definable comparator threshold. Although the electronics is normally configured for bidirectional 'straight through' transit time measurements with a pair of transducers, calibration operations in echo mode are also possible as in the case of the angled flowmeter geometry, as discussed in section 5 .

The HV bias for the vibrating foils of the capacitative transducers, settable in the range $+80 \rightarrow+360 \mathrm{~V}$, is generated by a DC-DC converter. The ultrasonic interface board with the DCDC conversion and energy storage capacitors for the transducer $\mathrm{HV}$ excitation is shown on the right of figure 21 .

When transmitting, a transducer can be excited (depending on the mode selected in the firmware of the microcontroller) with either a single negative-going HV square pulse or by a train of up to 8 pulses (figure 2). The excitation pulses are built by combining $50 \mathrm{kHz}$ TTL pulses from the microcontroller with the DC-DC converter output. When receiving, a transducer is biased with a flat HVDC voltage and its signal passed to a differential amplifier with a virtual ground and programmable gain, followed by a comparator. During a firmware-defined interval in the range 200-300 $\mu$ s following transmission the comparator output is "blanked" - to eliminate the effects of noise pickup and higher velocity sound propagation through the metal envelope of the instrument 

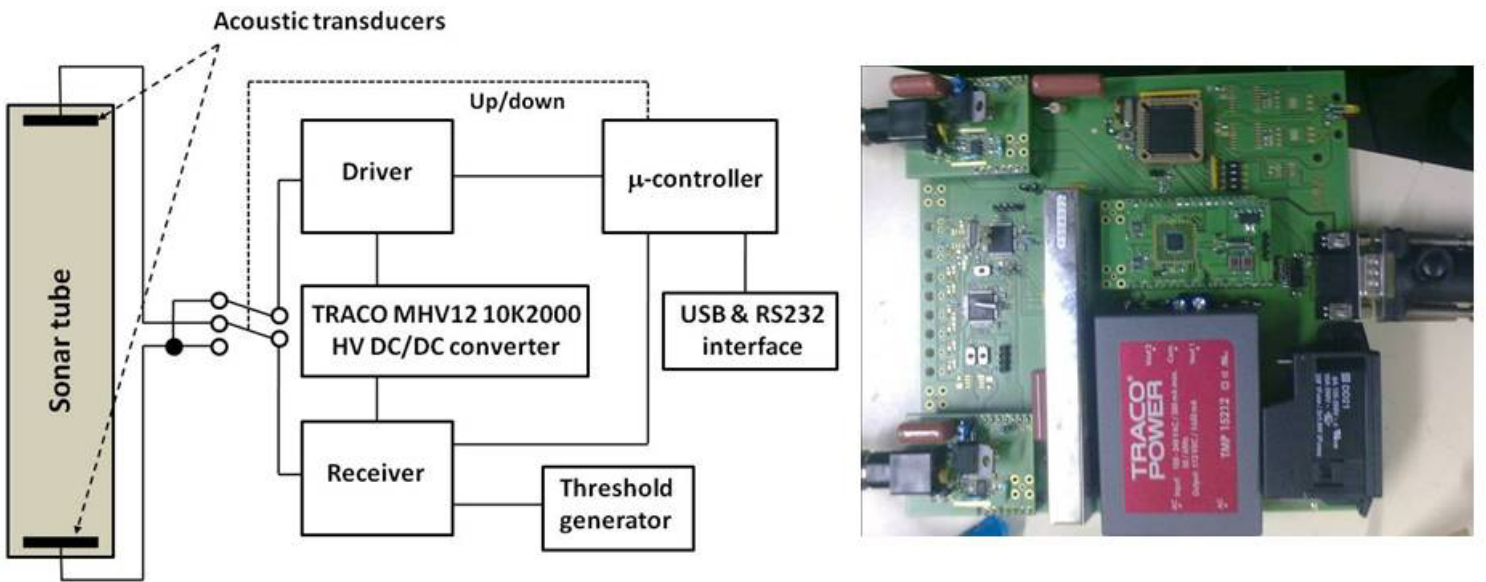

Figure 21. Left: block diagram of the bidirectional time-of-flight measuring electronics. Right: implementation.

during the cycling of the transmitting transducer. We have found "ringing" the transmitter with a single pulse to a be useful technique to minimise the "blanking" period, particularly where short transmission times are used, as for example in the echo mode of distance calibration of transducers in the angled flowmeter (section 5).

The upper trace of figure 22 illustrates the response of the receiving SensComp 604142 transducer biased at $+330 \mathrm{~V}$ when the identically-biased transmitting transducer is excited or "rung" with a single negative HV pulse of $10 \mu$ s duration. The lower trace illustrates the signal after amplification (gain $\times 150$ ). The signal was transmitted through $666 \mathrm{~mm}$ of nitrogen at a pressure of 1 bar $_{\text {abs. }}$.

Sound transit times are computed from the number of $40 \mathrm{MHz}$ pulses counted between the rising edge of the first transmitted $50 \mathrm{KHz}$ sound pulse, and the time the first received, amplified sound pulse crosses the comparator threshold. Transit times, computed alternately in the two transmission directions are continuously entered into an internal FIFO memory. When a measuring cycle is requested by the supervisory computer a time-stamped running average from the 300 most recent transit times in each direction in the FIFO memory is output, together with the average temperature and pressure, at a rate of up to 20 averaged samples per second.

In addition to the $\mathrm{I} / \mathrm{O}$ connectivity for communications, the ultrasonic transducers, pressure and temperature sensors, the local instrument electronics incorporates two (4-20 mA) analog outputs to provide feedback for adjustment of the $\mathrm{C}_{3} \mathrm{~F}_{8} / \mathrm{C}_{2} \mathrm{~F}_{6}$ mixing ratio by the external gas mixture control system.

Data is taken by the Supervisory, Control and Data Acquisition (SCADA) computer over a serial bus running under USB or RS232. Future versions of the electronics will implement Ethernet or CANbus running the CANOpen communication protocol. The SCADA software - implemented as a PVSS-II project [8] — sends various commands to the local electronics to start, stop or reset the instrument, and retrieve data from the FIFO memory.

The analyzing software which processes the data, makes analyses and generates control signals to the electronics is described in section 6. 


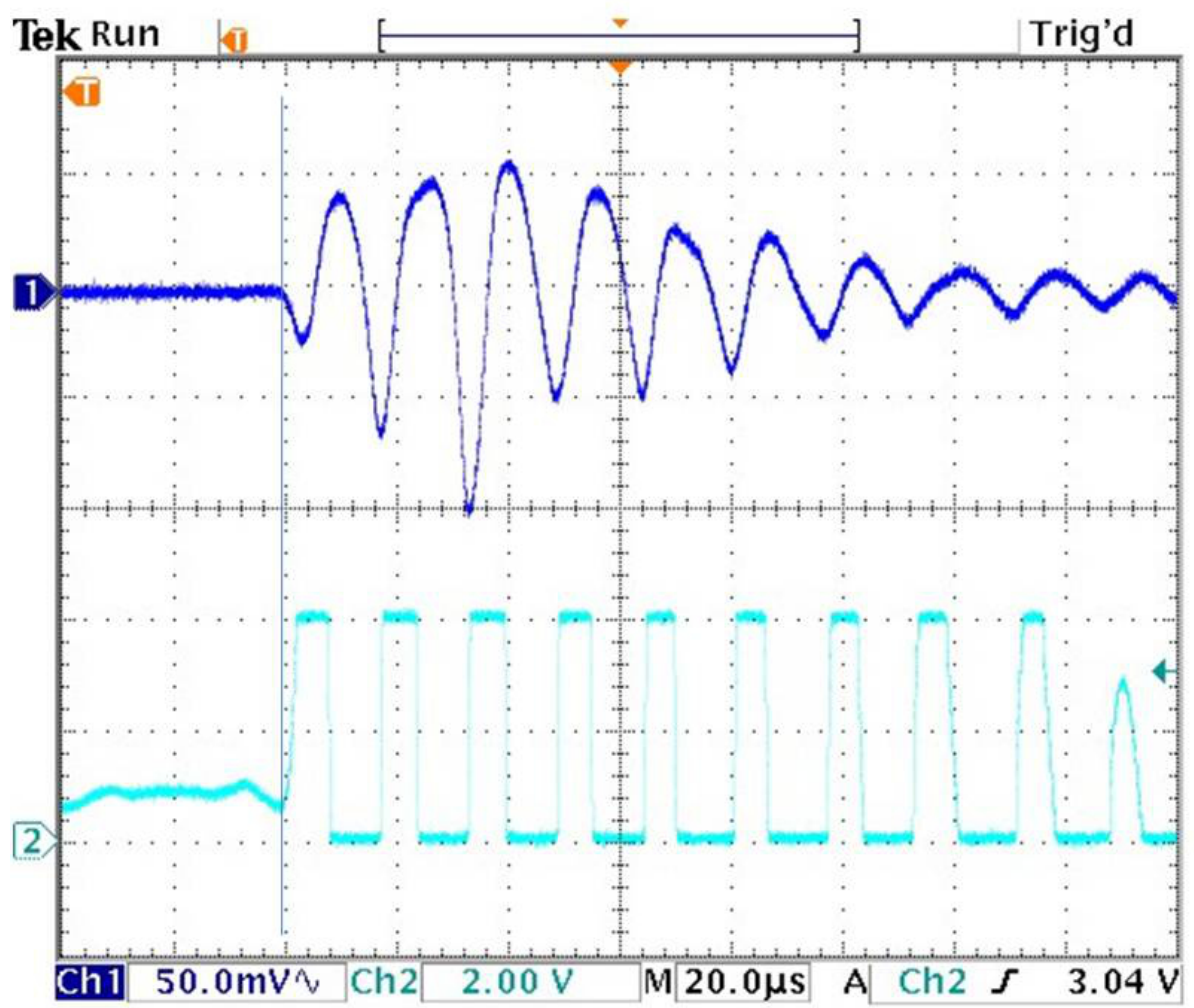

Figure 22. Oscillogram showing: upper trace — signal from a SensComp 604142 ultrasonic transducer in response to "ringing" an identical transmitting transducer with a single $10 \mu$ s duration negative-going square wave (both transducers with $330 \mathrm{~V}$ bias): lower trace - signal after $\times 150$ amplification.

\section{Transducer inter-distance calibration and transit time uncertainty estimation}

For high precision mixture and flow analysis the uncertainty in the sound flight distance should be minimized. Following transducer installation it is necessary to perform a transducer foil interdistance calibration. The most convenient method is to calculate this distance using measured sound transit times with the tube filled with a pure gas (or gases) having well-known sound velocity dependence on temperature and pressure. We initially made calibrations of the 'pinched axial' instruments using xenon, whose sound velocity and $\mathrm{mw}\left(175.5 \mathrm{~ms}^{-1}\right.$ at $20^{\circ} \mathrm{C}, 137$ units - figure 1) are closest $[14,15]$ to those of the fluorocarbon mixtures in the ATLAS application [1], and whose thermo-physical behaviour is that of an ideal gas. Later calibrations demonstrated sufficient precision with nitrogen and argon, which are considerably cheaper and more widely available. The typical precision in transducer inter-distance measured in this way is $\pm 0.1 \mathrm{~mm}$.

We are presently using the simplest technique for transit time measurement, with a single comparator. The threshold level must be low enough not to miss the first rising edge yet high enough not to trigger on noise. The threshold crossing time is delayed relative to the true pulse arrival time. In early calibrations with reference gases the threshold was scanned down to the point at which noise triggered the random stopping of the $40 \mathrm{MHz}$ transit time clock, then backed up to get out of the noise. The slope and shape of the rising edge of the of the first received sound pulse - shown 
in figure 22 - was found to be constant over a wide range of excitation amplitude (200-300 V). A threshold level of $\sim 15 \mathrm{mV}$ - referenced to the receiving transducer output — was found to give a stable transit time 50-75 ns longer than the minimum value that was intermittently seen through the random noise-induced stops when lower thresholds were used. This threshold was found satisfactory for static measurements and measurements with flow in all the gases considered in this work. We combine this error with the $25 \mathrm{~ns}$ transit time clock resolution to quote a conservative estimate for the timing uncertainty of $100 \mathrm{~ns}$. In future electronics developments we plan to investigate a multi-threshold implementation aimed at reconstructing the rising edge of the first sound pulse to better extrapolate to its start time.

As a precursor to the measurements in $\mathrm{C}_{3} \mathrm{~F}_{8} / \mathrm{C}_{2} \mathrm{~F}_{6}$ mixtures, transducer inter-distance calibration was followed with measurements in pure $\mathrm{C}_{3} \mathrm{~F}_{8}$ and $\mathrm{C}_{2} \mathrm{~F}_{6}$. The average difference between measured sound velocities and the predictions [16-18]) was less than $0.04 \%$ in both pure fluids, and was a strong indicator of a correct transducer inter-distance calibration.

A similar transducer inter-distance calibration procedure will be used in the angled high flow ultrasonic analyzer/flow meter. This configuration must allow for the possible replacement of transducers without interruption of the high vapour flow of around $200001 . \mathrm{min}^{-1}$. A transducer may be replaced following closure of the quarter-turn ball valve in the transverse sound tube (as illustrated in figure 19). Following transducer re-installation the air is evacuated from the closed stub of tube outboard of the closed ball valve and the calibration gas injected. The electronics is able to operate in echo mode to find the distance between the transducer foil and the equator of the ball in the closed valve. The calibration gas is then evacuated and the valve is opened to bring the new transducer into contact with the process gas.

The total sound path can be measured with the valves open and the flowmeter filled with static calibration gas before the start of operations with fluorocarbon vapour: the distances of the two transducers from the equators of their valves are subtracted from the total path length to find the distance between the outboard equators of the two ball valves. This distance is assumed to be a 'hard parameter', remaining unchanged following any subsequent transducer replacement.

\section{SCADA and analysis software}

The specialized software for the gas analyzer operation - illustrated in figure 23 - is coded as a standalone component in the PVSS II, v3.8 SCADA environment $[8,16]$; a standard at CERN.

The main tasks of the software include:

- vapour flow rate determination;

- sound velocity and molar mixture concentration determination;

- communication with the custom electronics, to start and stop the measuring cycle, and to request time-stamped bidirectional sound transit times, temperature and pressure data from the instrument FIFO memory;

- calculation and transmission of the set-points for the analog (4-20mA) output signals for $\mathrm{C}_{3} \mathrm{~F}_{8} / \mathrm{C}_{2} \mathrm{~F}_{6}$ ratio adjustment in the external cooling plant; 


\section{SCADA Software}

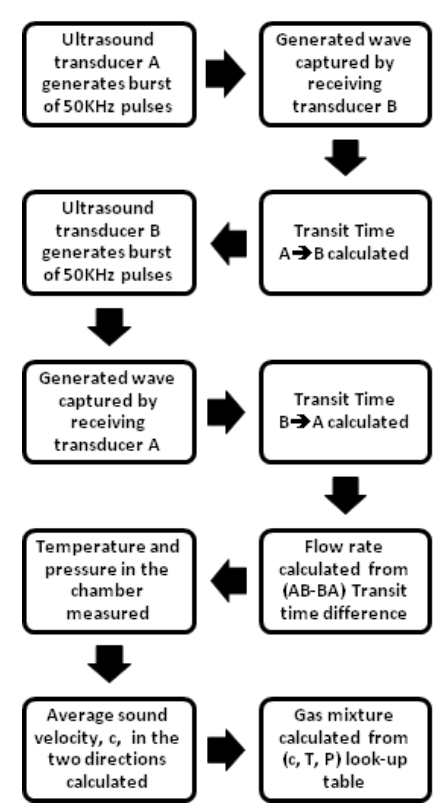

Measuring chain schematics

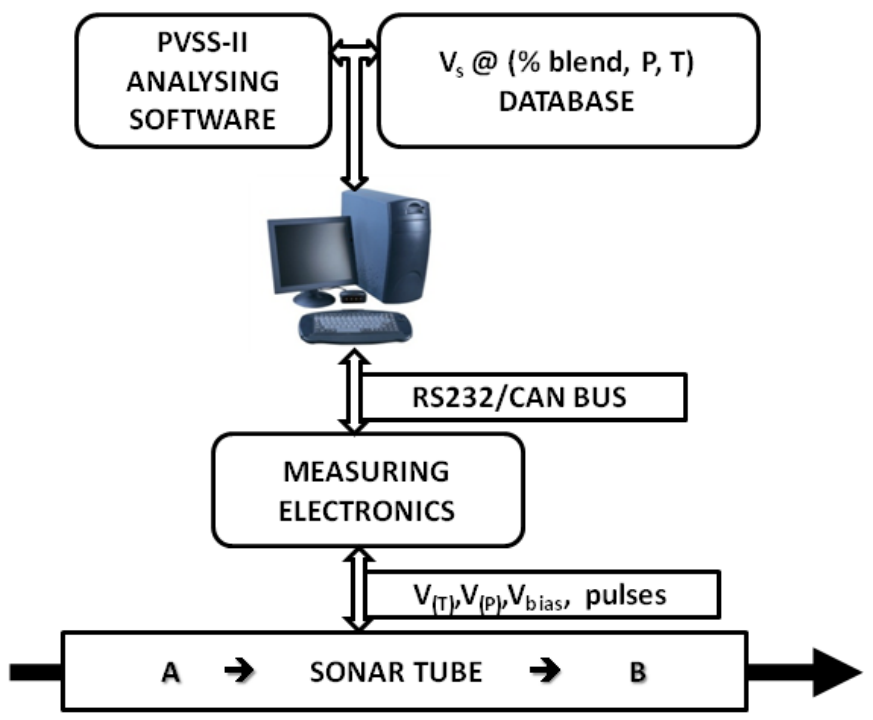

Figure 23. The main activities of the PVSS-II SCADA software of the gas analyzer/flow meter.

- visualization via a Graphical User Interface (GUI);

- archiving of sound transit times, velocities, flow, mixture composition, temperature and pressure into a local and/or remote data base;

- in the angled flowmeter an echo mode for locating the distance of the transducers from their closed ball valves during calibration with a quasi-ideal gas (section 5).

The present software [16] for $\mathrm{C}_{3} \mathrm{~F}_{8} / \mathrm{C}_{2} \mathrm{~F}_{6}$ mixture analysis uses a pre-loaded look-up table of NISTREFPROP generated sound velocity with $0.25 \%$ granularity in $\mathrm{C}_{3} \mathrm{~F}_{8} / \mathrm{C}_{2} \mathrm{~F}_{6}$ molar mixture and covering the expected range of temperature and pressures $\left(16.2 \rightarrow 26.1{ }^{\circ} \mathrm{C}, 800 \rightarrow 1600\right.$ mbar $_{\text {abs }}$ with $0.3^{\circ} \mathrm{C} \& 50$ mbar granularity). These conditions correspond to the superheated $\mathrm{C}_{3} \mathrm{~F}_{8} / \mathrm{C}_{2} \mathrm{~F}_{6}$ binary gas mixture environment in the vapour return line some tens of metres from the evaporative zone within the silicon tracker.

The algorithm calculates mixture composition by minimizing a quadratic norm, $n_{i}$, for each $\left(c_{i}, T_{i}, P_{i}\right)$ table entry:

$$
n_{i}=k_{1}\left(p_{i, \text { table }}-p_{\text {running average }}\right)^{2}+k_{2}\left(t_{i, \text { table }}-t_{\text {running average }}\right)^{2}+k_{3}\left(c_{i, \text { table }}-c_{\text {running average }}\right)^{2}
$$

where $p, t \& c_{\text {running average }}$ are real-time outputs of the instrument FIFO memory and $k_{1,2,3}$ are weights [16] that express the dependency of the mixture prediction on the error that comes from the differences between the table and measured $c, T$ or $P$ values.

An expanded software version $[16,19]$ will implement a $\mathrm{C}_{3} \mathrm{~F}_{8} / \mathrm{C}_{2} \mathrm{~F}_{6}$ database covering a much larger $c, T, P$ range, from near the critical temperature and pressure down to the expected thermosiphon condenser temperature and pressure of $-70^{\circ} \mathrm{C}$ and 300 mbar $_{\text {abs }}$. This development forms 
part of an ongoing study $[7,14]$ to feed back improved $\mathrm{C}_{3} \mathrm{~F}_{8} / \mathrm{C}_{2} \mathrm{~F}_{6}$ thermophysical data into NISTREFRPOP [5] AND PC-SAFT models. The software will allow "zooming" to smaller sub-tables $(O \sim 10,000 c, T, P$ data points), corresponding to a narrower process range - as in the present application - in various $\mathrm{C}_{3} \mathrm{~F}_{8} / \mathrm{C}_{2} \mathrm{~F}_{6}$ mixtures.

The expanded database will also include air/fluorocarbon mixtures over a temperature and pressure range centred on thermosiphon condenser conditions [9]. This database will provide a look up table to determine the level of air ingress into the sub-atmospheric pressure condenser. Look-up table data will be gathered from prior measurements in calibration mixtures and from theoretical data using equation of state predictions.

\section{Conclusion}

We have developed a combined, real-time ultrasonic flow meter and binary gas analyzer with custom electronics and dedicated SCADA software running under PVSS-II, a CERN standard. The instrument has been developed in two geometries following extensive computational fluid dynamics studies of various mechanical layouts. A version with an axial sound path has been used with binary gas flows up to $2301 . \mathrm{min}^{-1}$, while a version with a sound path angled at $45^{\circ}$ to the gas flow direction has been developed for use in gas flows up to $200001 . \mathrm{min}^{-1}$.

The binary gas composition measurement revealed a resolution of $3.10^{-3}$ for mixtures of $\mathrm{C}_{3} \mathrm{~F}_{8}$ with $\mathrm{C}_{2} \mathrm{~F}_{6}(80 \% / 20 \%)$ - adequate for a blend control system [19] — while a sensitivity of $<$ $5.10^{-5}$ to traces of $\mathrm{C}_{3} \mathrm{~F}_{8}$ in nitrogen is seen in an instrument that has been in continuous operation for more than one year. These measurements have demonstrated the higher mixture precision possible in mixtures of gases with components of increasingly-different molecular weights: the $\mathrm{C}_{3} \mathrm{~F}_{8} / \mathrm{C}_{2} \mathrm{~F}_{6}$ and $\mathrm{C}_{3} \mathrm{~F}_{8} / \mathrm{N}_{2}$ combinations respectively having molecular weight differences of 50 and 160 .

Flow measurements in the instrument implemented in a pinched axial geometry have been compared with two commercial devices operating according to different physical principles. A flow resolution of $0.3 \%$ of full scale was seen in comparison with a Bronkhorst F-113AC-AAD99-V thermal flowmeter for flows up to $901 . \mathrm{min}^{-1}$ while a flow resolution of $1 \%$ of full scale was seen in comparison with a Schlumberger Delta G16 volumetric gas meter for flows up to $2301 . \mathrm{min}^{-1}$.

An instrument with an angled sound path geometry has been developed for installation in the vapour return path of the $60 \mathrm{~kW}$ thermosiphon recirculator currently under construction for the ATLAS silicon tracker where high fluorocarbon flow rates (up to $200001 . \mathrm{min}^{-1}$ ) and velocities (up to $22 \mathrm{~ms}^{-1}$ ) are expected. Computational fluid dynamics studies were made to determine the preferred geometry, including transducer spacing and placement, together with the sound path crossing angle with respect to the vapour flow direction. A preferred geometry with a main tube inner diameter of $137 \mathrm{~mm}$ and a sound crossing angle of $45^{\circ}$ has been chosen. Tests in air (in comparison with an Amprobe TMA10A commercial anemometer) of a $45^{\circ}$ prototype built in PVC tube of similar diameter have demonstrated a flow measurement precision of $\pm 1.9 \%$ of the full scale linear flow of $15 \mathrm{~ms}^{-1}$. The production of a stainless steel variant of the instrument has started and further closed circuits tests with fluorocarbons are planned. 
A further variant of the instrument, under development to allow the detection and elimination of incondensable vapour accumulating in the condenser of a fluorocarbon recirculator [9] will be reported in a future publication.

The instruments described in this work have many potential applications, including the analysis and flowmetry of hydrocarbons, vapour mixtures for semi-conductor manufacture and anaesthetic gas mixtures.

\section{Acknowledgments}

The authors wish to thank CERN and their home institutes for support for this project. University of Indiana participation was supported through U.S. Department of Energy contract DE-AC0298CH10886. University of Oklahoma participation was supported through DOE contract DEFG02-04ER41305. A. Bitadze acknowledges support for his PhD research from the ATLAS inner detector group and the particle physics group of the University of Glasgow. R. Bates acknowledges support from the U.K. Science and Technology Facilities Council. M. Doubek, V. Vacek and M. Vitek acknowledge individual support and support for this project through the following grants in the Czech Republic: MSM grants 6840770035 \& LA08015 and SGS/FIS grant10-802460 of the Czech Technical University, Prague. We also thank Jaroslav Vavra of the SLAC National Accelerator Laboratory for valuable discussions at the outset of this project.

\section{References}

[1] D. Attree, B. Anderson, E. Anderssen, V. Akhnazarov, R. Apsimon, et al., The evaporative cooling system for the ATLAS inner detector, 2008 JINST 3 P07003.

[2] G. Viehhauser, Evaporative cooling in ATLAS - present and future, Nucl. Instr. Meth. A 628 (2011) 251.

[3] ATLAS collaboration, Inner Detector technical design report, vols 1\&2, CERN-LHCC-97-016 \& 17.

[4] ATLAS collaboration, Pixel Detector technical design report, CERN-LHCC-98-13.

[5] E. Lemmon, M. Huber and M. McLinden, 'REFPROP' Standard reference database 23, version 9.0, U.S. National Institute of Standards and Technology (2010).

[6] G. Hallewell, G. Crawford, D. McShurley, G. Oxoby and R. Reif, A sonar-based instrument for the ratiometric determination of binary gas mixtures, Nucl. Instr. Meth. A 264 (1988) 219.

[7] G. Hallewell, V. Vacek and V. Vins, Properties of saturated fluorocarbons: experimental data and modeling using perturbed-chain-SAFT, Fluid Phase Equilib. 292 (2010) 64.

[8] PVSS II - Process visualization and control system, version 3.8 (2009) ETM professional control GmbH, A-7000, Eisenstadt, Austria http://www . etm . at/.

[9] J. Botehlo-Direito et al., General description of the full scale thermosiphon cooling system for ATLAS SCT and Pixel detectors, CERN EN-CV Report, document 1083852 ver.1 (27 November 2010); M. Battistin et al., 5th ATLAS Thermo-siphon cooling workshop, CERN, October 20, 2011.

[10] OpenFOAM $₫$, The open source computational fluid dynamics toolbox, version 2.1.0 (2011).

[11] F.R. Menter, Two-equation eddy-viscosity turbulence models for engineering applications, AIAA J. 32 (1994) 1598. 
[12] E. Lemmon and R. Span, Short fundamental equations of state for 20 fluids, J. Chem. Eng. Data 51 (2006) 785 .

[13] G. Bozza and E. Da Riva, Simulation results for the combined ultrasonic flow meter and binary vapour mixture analyser for the ATLAS silicon tracker, CERN EN-CV Report, document 1180058 ver.3 (25 April 2012).

[14] V. Vacek, G. Hallewell and S. Lindsay, Velocity of sound measurements in gaseous per-fluorocarbons and their mixtures, Fluid Phase Equilibr. 185 (2001) 305.

[15] V. Vacek, G. Hallewell, S. Ilie and S. Lindsay, Perfluorocarbons and their use in cooling systems for semiconductor particle detectors, Fluid Phase Equilibr. 174 (2000) 191.

[16] R. Bates et al., An acoustic fluorocarbon coolant mixture analyzer for the ATLAS silicon tracker, in proc. of 2nd International conference on Advancements in Nuclear Instrumentation, Measurement Methods and their Applications (ANIMMA) Ghent, Belgium, 6-9 June, 2011, IEEE Trans. Nucl. Sci. 59 (2012) 2367.

[17] G. Hallewell, V. Vacek and M. Doubek, Novel and simple sonar gas analyzers, in proc. of 9th Asian Thermophysical Properties Conference, Beijing, October 19-22, 2010, CD ROM Paper 109296: 1-6 (2010).

[18] A. Bitadze et al., A combined on-line acoustic flow meter and fluorocarbon coolant mixture analyzer for the ATLAS silicon tracker, in proc. of 13th International Conference on Accelerator and Large Experimental Physics Control Systems (ICALEPS2011) Grenoble, 10-14 October 2011.

[19] R. Bates et al., The study of $C_{2} F_{6} / C_{3} F_{8}$ saturated fluorocarbon refrigerant blends for the ATLAS Silicon tracker, paper to be submitted to JINST. 